Gaofeng Shao, Yucao Lu, Dorian A. H. Hanaor, Sheng Cui, Jian Jiao, Xiaodong Shen

\title{
I mproved oxidation resistance of high emissivity coatings on fibrous ceramic for reusable space systems
}

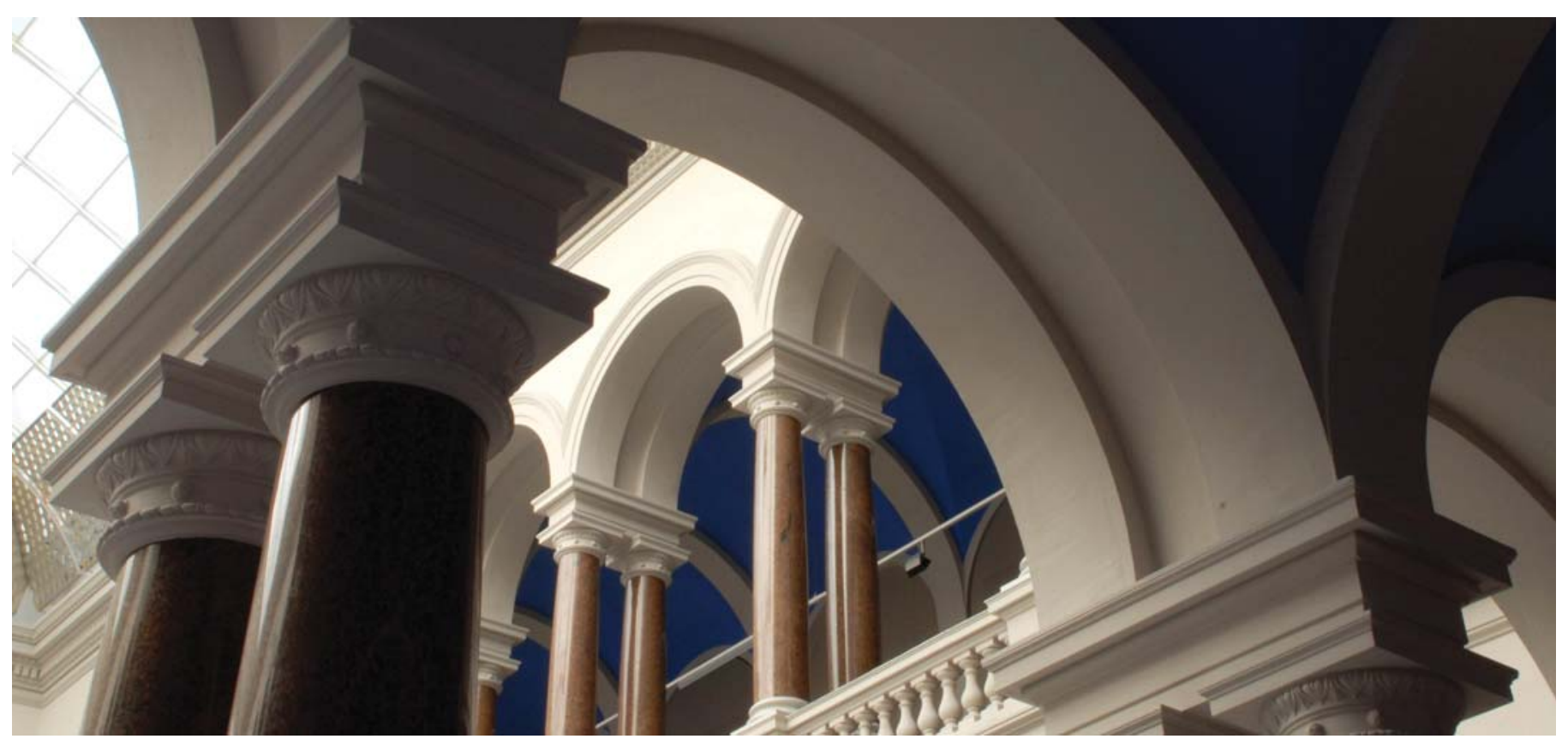

Shao, Gaofeng; Lu, Yucao; Hanaor, Dorian A. H.; Cui, Sheng; Jiao, Jian; Shen, Xiaodong: Improved oxidation resistance of high emissivity coatings on fibrous ceramic for reusable space systems. Corrosion Science 146 (2019): 233-246. https://doi.org/10.1016/j.corsci.2018.11.006 


\title{
Improved oxidation resistance of high emissivity coatings on fibrous ceramic for reusable space systems
}

\author{
Gaofeng Shao ${ }^{a, b, c, *}$, Yucao Lu ${ }^{a, b}$, Dorian A. H. Hanaor ${ }^{c}$, Sheng Cui ${ }^{a, b}$, Jian Jiao ${ }^{\text {d }}$, Xiaodong Shen ${ }^{a, b, *}$ \\ a. State Key Laboratory of Materials-Oriented Chemical Engineering, College of Materials Science and \\ Engineering, Nanjing Tech University, Nanjing 210009, China \\ b. Jiangsu Collaborative Innovation Center for Advanced Inorganic Function Composites, Nanjing 210009, China \\ c. Fachgebiet Keramische Werkstoffe, Institut für Werkstoffwissenschaften und -technologien, Technische \\ Universität Berlin, Berlin 10623, Germany \\ d. National Key Laboratory of Advanced Composite, Beijing Institute of Aeronautical Materials, Beijing 101300 , \\ China
}

*Corresponding authors: Gaofeng Shao, Xiaodong Shen

Tel.: +86 25 83587234; fax: +862583221690

E-mail addresses:

Gaofeng.shao@ceramics.tu-berlin.de (G. Shao),

xdshen@njtech.edu.cn (X. Shen)

\begin{abstract}
:
To develop high emissivity coatings on fibrous ceramic substrates with improved thermal resistance for reusable space systems, $\mathrm{WSi}_{2}-\mathrm{MoSi}_{2}-\mathrm{Si}-\mathrm{SiB}_{6}$-borosilicate glass coatings were prepared on fibrous $\mathrm{ZrO}_{2}$ by slurry dipping and subsequent high temperature rapid sintering. A coating with $20 \mathrm{wt} \% \mathrm{WSi}_{2}$ and $50 \mathrm{wt} \% \mathrm{MoSi}_{2}$ presents optimal thermal stability with only $10.06 \mathrm{mg} / \mathrm{cm}^{2}$ mass loss and $4.0 \%$ emissivity decrease in the wavelength regime $1.27-$ $1.73 \mu \mathrm{m}$ after $50 \mathrm{~h}$ oxidation at $1773 \mathrm{~K}$. The advantages of double phase metal-silicide coatings combining $\mathrm{WSi}_{2}$ and $\mathrm{MoSi}_{2}$ include improved thermal compatibility with the substrate and an enhanced glass-mediated self-healing ability.
\end{abstract}

Keywords: glass; intermetallic; XPS; Oxidation; Oxide coatings

\section{Introduction}

Fibrous ceramics are of growing interest in aerospace applications, particularly towards reusable thermal protection systems (RTPSs) in next generation hypersonic vehicles, due to their attributes of low density, low thermal conductivity and high thermal stability [1]. A typical concept for a RTPS structure comprises a high emissivity coating (HEC) on the surface of low thermal conductivity fibrous ceramic insulation, facilitating radiative cooling while minimizing heat conduction. In the past few years, fibrous $\mathrm{ZrO}_{2}$ ceramics have been the subject of increasing attention towards thermal insulation applications in ultra-high temperature environments because of their higher temperature stability relative to fibrous quartz or mullite ceramics [2]. Consequently, HEC materials with similarly high thermal stability are sought to complement fibrous $\mathrm{ZrO}_{2}$ insulation materials in RTPSs.

Among existing coating systems, single phase $\mathrm{MoSi}_{2}$ based HECs have been applied successfully on the surfaces of various substrates including fibrous $\mathrm{SiO}_{2}$, 
Shao, Gaofeng, et al. "Improved oxidation resistance of high emissivity coatings on fibrous ceramic for reusable space systems." Corrosion Science 146 (2019): 233-246.

mullite and $\mathrm{ZrO}_{2}$ ceramics, with favorable emissivity levels of 0.85 and higher achieved [3-10]. In our previous work, $\mathrm{MoSi}_{2}$-borosilicate glass coating prepared on fibrous $\mathrm{ZrO}_{2}$ ceramic showed excellent thermal shock behavior between room temperature and $1673 \mathrm{~K}$ [8], and following the inclusion of $\mathrm{ZrO}_{2}$ in the coating material, this thermal shock resistance was extended to $1773 \mathrm{~K}$ [9]. However, the emissivity values of both coating types were only moderately higher than 0.8 , and the coating surfaces were nearly fully oxidized following thermal shock tests, which had a negative effect on radiative performance. Recently, the inclusion of $\mathrm{TaSi}_{2}$ in $\mathrm{MoSi}_{2}$ based HEC systems was explored and was found to alter their radiative properties and thermal endurance $[7,11]$. Specifically, in our previous research, a metal silicide-glass hybrid coating was prepared on fibrous $\mathrm{ZrO}_{2}$ by a rapid sintering method [11]. The coating, comprising an outer $\mathrm{Ta}-\mathrm{Si}-\mathrm{O}$ glass layer and a dense $\mathrm{MoSi}_{2}-\mathrm{TaSi}_{2}$-glass inner layer was found to be thermally stable in air at $1773 \mathrm{~K}$ in air for $50 \mathrm{~h}$, with a total emissivity around 0.9 in the $0.3-2.5$ $\mu \mathrm{m}$ wavelength regime. Its thermal stability and consistent emissivity were attributed to the optimized viscosity of the Ta-Si-O layer and the self-healing ability of the $\mathrm{MoSi}_{2}-\mathrm{TaSi}_{2}$-glass. To date, most investigations on high emissivity transition-metal disilicides have focused on $\mathrm{MoSi}_{2}$ and $\mathrm{TaSi}_{2}$, while $\mathrm{WSi}_{2}$ has received relatively limited attention. The interactions of $\mathrm{MoSi}_{2}$ and $\mathrm{WSi}_{2}$ have not been reported in terms of emissive performance and the thermal stability of radiative properties has not been adequately studied in such systems. This is particularly important as ablation and oxidation alter the surface composition and microstructure of coatings, which may affect their radiative performance [12, 13]. Towards aerospace applications, HECs are required with intrinsic high temperature oxidation resistance, which limits the attenuation of coating emissivity during long-term exposure to high temperature oxidative atmospheres. In general, defect formation and defect healing occur competitively during the oxidation process $[14,15]$. Owing to the formation of a flowing glass phase at high temperatures, defects are healed to a certain extent, thus limiting the oxidation driven degradation of emissive phases and preserving performance. The self-healing ability of glass phase is determined not only by its relative quantity, but also its viscosity. For this reason viscosity is one of the most important properties for the glass phase generated on the coating surface during high temperature oxidation[16]. Amorphous $\mathrm{SiO}_{2}$ is known to exist as a dense and highly viscous glass, which is strongly networked due to the sharing of oxygen atoms between neighboring $\mathrm{SiO}_{4}$ tetrahedra. Boron, added as $\mathrm{B}_{2} \mathrm{O}_{3}$, acts as a network modifier in $\mathrm{SiO}_{2}$ and reduces its viscosity by the production of nonbridging oxygen atoms (NBO). Accordingly, borosilicate glass has emerged as a promising oxidation resistant sealant material, due to its low oxygen permeability, appropriate viscosity and fluidity $[17,18]$, which plays a critical role in sealing defects of coatings towards oxidation.

In this work, in order to improve thermal resistance of HECs on fibrous $\mathrm{ZrO}_{2}, \mathrm{MoSi}_{2}$ and $\mathrm{WSi}_{2}$ were simultaneously introduced as double phase emissive agents. $\mathrm{WSi}_{2}-\mathrm{MoSi}_{2}-\mathrm{Si}-\mathrm{SiB}_{6}$-borosilicate glass multiphase coatings with different compositions were prepared by slurry dipping and subsequent high temperature rapid sintering. Specimens were exposed to a high temperature oxidizing atmosphere for $50 \mathrm{~h}$. Microstructure, phase composition and radiative properties, before and after oxidation, were investigated and the oxidation mechanism was examined.

\section{Experimental}

\subsection{Preparation of the coatings}

Fibrous $\mathrm{ZrO}_{2}$ ceramics with dimensions of $25 \mathrm{~mm} \times 25$ $\mathrm{mm} \times 5 \mathrm{~mm}$ (Anhui Crystal New Materials Co. Ltd., China) were used as substrates. The coatings were prepared by slurry dipping and rapid sintering. Firstly, borosilicate glass (BSG) was prepared by high temperature melting and water quenching, as reported in our previous work [8]. Then, a slurry was prepared by ball-milling as follows: $\mathrm{MoSi}_{2}, \mathrm{WSi}_{2}, \mathrm{BSG}, \mathrm{Si}, \mathrm{SiB}_{6}$, ethanol and a $1 \mathrm{wt} \%$ aqueous solution of carboxyl methylcellulose (CMC) were mixed in a nylon ballmill and milled for $6 \mathrm{~h}$ at a rotation speed of $400 \mathrm{rpm}$. The mass ratio of the powders, ethanol, CMC aqueous 
Shao, Gaofeng, et al. "Improved oxidation resistance of high emissivity coatings on fibrous ceramic for reusable space systems." Corrosion Science 146 (2019): 233-246.

solution and zirconia balls was 1.4:1:0.25:2. Coatings were prepared on the top surfaces and four sides of treated fibrous $\mathrm{ZrO}_{2}$ substrates by slurry dipping: the top surface and two opposing sides were dip-coated first, and then the coated sample was dried at $333 \mathrm{~K}$ for $30 \mathrm{~min}$ and removed to immerse the other two sides. The coating thickness was controlled by repeating such dipping four times, and the dwell time for each dipping was 2 s. Following these dipping cycles, the coated samples were dried at $333 \mathrm{~K}$ for $12 \mathrm{~h}$ and then at $373 \mathrm{~K}$ for $6 \mathrm{~h}$. Finally, the fully dried samples were fired in a pre-heated furnace at $1773 \mathrm{~K}$. The samples were held for $15 \mathrm{~min}$ in natural air and later removed from the furnace for rapid cooling. The compositions and sample names of the powders are shown in Table 1. Samples are referred to in terms of their respective weight percentages of $\mathrm{WSi}_{2}$ and/or $\mathrm{MoSi}_{2}$.

Table 1. Compositions and labels of the coatings studied in this work

\begin{tabular}{llllll}
\hline \multirow{2}{*}{ Samples } & \multicolumn{5}{l}{ Composition $($ Wt. \%) } \\
\cline { 2 - 6 } & MoSi $_{2}$ & WSi $_{2}$ & Borosilicate glass & Si & SiB $_{\mathbf{6}}$ \\
M70 & 0 & 70 & 18.5 & 10 & 1.5 \\
M35W35 & 20 & 50 & 18.5 & 10 & 1.5 \\
M50W20 & 35 & 35 & 18.5 & 10 & 1.5 \\
M70 & 50 & 20 & 18.5 & 10 & 1.5 \\
\hline
\end{tabular}

\subsection{Isothermal oxidation}

The high temperature oxidation resistance of coated fibrous $\mathrm{ZrO}_{2}$ specimens were investigated by a static isothermal oxidation test, which was carried out in ambient air at $1773 \mathrm{~K}$. Coated specimens were loaded on a $\mathrm{ZrO}_{2}$ refractory brick and transferred into a furnace that had been pre-heated to $1773 \mathrm{~K}$. Specimens were then taken out at designated times $(1 \mathrm{~h}, 5 \mathrm{~h}, 10 \mathrm{~h}$, $20 \mathrm{~h}$ and $50 \mathrm{~h}$ ) and cooled to room temperature. Coated specimens were weighed with $\pm 0.1 \mathrm{mg}$ accuracy and returned to the furnace for further isothermal oxidation tests. The mass change per unit area at different oxidation times were calculated according to eq. (1) and averaged over three specimens.

$$
\Delta W=\frac{m_{0}-m_{1}}{A}
$$

Here, $\Delta W$ is the mass change per unit area; $m_{0}$ and $m_{1}$ are the weights of the specimens before and after oxidation, respectively; and $A$ is the surface area of the coated sample.

\subsection{Radiative properties}

Reflectance spectra in the wavelength range of 0.3-2.5 $\mu \mathrm{m}$ were obtained by ultraviolet-visible-near infrared spectrophotometer (UV-Vis-NIR, Cary 5000, Varian, CA) equipped with a $\mathrm{BaSO}_{4}$ integrating sphere. The reflectance spectra in the wavelength range of 2.5-15 $\mu \mathrm{m}$ were by Fourier transform infrared spectroscopy (FT-IR, Frontier, PerkinElmer LLC) equipped with a gold-coated integrating sphere. The emissivity is obtained indirectly from the measured reflectance based on the relationship of materials, $\varepsilon=\mathrm{A}=1-\mathrm{R}-\mathrm{T}$, where $\varepsilon, \mathrm{A}, \mathrm{R}$ and $\mathrm{T}$ are the emissivity, absorptivity, reflectivity, and transmissivity respectively. The total emissivity can be derived from the reflectance spectrum according to Eq. (2)

$$
\varepsilon_{\mathrm{T}}=\frac{\int_{\lambda_{1}}^{\lambda_{2}}[1-R(\lambda)] P_{\mathrm{B}}(\lambda) \mathrm{d} \lambda}{\int_{\lambda_{1}}^{\lambda_{2}} P_{\mathrm{B}}(\lambda) \mathrm{d} \lambda}
$$

Where $\lambda$ is the wavelength, $R(\lambda)$ is the reflectance, $P_{\mathrm{B}}$ $(\lambda)$ is given by Planck's law according to Eq. (3):

$$
P_{\mathrm{B}}(\lambda)=\frac{C_{1}}{\lambda^{5}\left[\exp \left(\frac{C_{2}}{\lambda T}\right)-1\right]}
$$

Where $C_{1}=3.743 \times 10^{-16} \mathrm{Wm}^{2}, C_{2}=1.4387 \times 10^{-2} \mathrm{mK}$. The calculation of the total emissivity was performed in a MATLAB environment using Eq. (2) and (3). 
Shao, Gaofeng, et al. "Improved oxidation resistance of high emissivity coatings on fibrous ceramic for reusable space systems." Corrosion Science 146 (2019): 233-246.

\subsection{Characterization}

Phase compositions of the coating surface were identified using a Rigaku Miniflex $\mathrm{X}$-ray diffractometer $(\mathrm{XRD})$ with $\mathrm{Cu}-\mathrm{K} \alpha$ radiation $(\lambda=$ $0.15406 \mathrm{~nm}$ ). The microstructure and the elemental distribution were characterized and analyzed by a scanning electron microscope (SEM, JSM-6510, JEOL, Japan) equipped with energy dispersive X-ray spectroscopy (EDS). The surface morphology was observed using a confocal laser scanning microscope (CLSM, Olympus LEXT OLS 4000, Japan). The CLSM images were obtained on a microscope powered by a singer laser $(\lambda=405 \mathrm{~nm})$ in the reflected light mode. X-ray photoelectron spectroscopy (XPS) spectra were obtained using a Theta Probe Thermo Fisher Scientific spectrometer with a monochromatic $\mathrm{Al} \mathrm{Ka}$ X-ray source $(1486.6 \mathrm{eV})$.

\section{Results}

3.1 Phase compositions and microstructures of the coatings

XRD patterns of the as-prepared coatings are shown in Fig.1. The coatings are composed of amorphous glass phase alongside tungsten or molybdenum silicides, $\mathrm{WSi}_{2}, \mathrm{MoSi}_{2}, \mathrm{~W}_{5} \mathrm{Si}_{3}$ and $\mathrm{Mo}_{5} \mathrm{Si}_{3}$, cristobalite $\mathrm{SiO}_{2}$, metallic $\mathrm{W}$ and Mo and small amounts of elemental Si. Metallic $\mathrm{W}$ or Mo and $\mathrm{W}_{5} \mathrm{Si}_{3}$ and $\mathrm{Mo}_{5} \mathrm{Si}_{3}$ phases are the oxidation products of disilicides following reactions (4) and (5) [19].

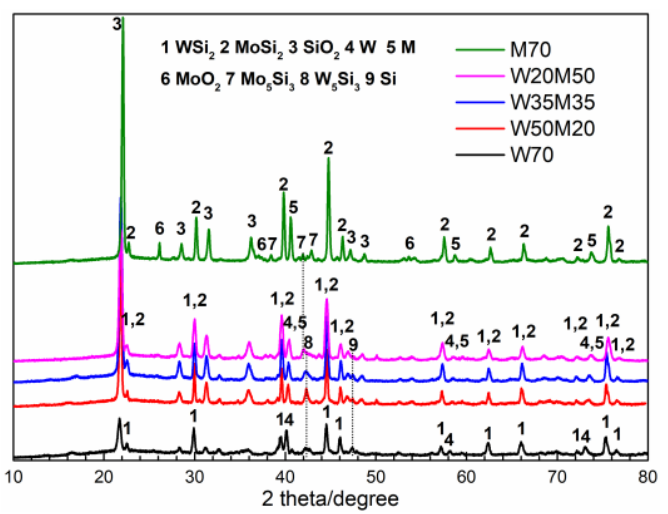

Fig.1 XRD patterns of the as-prepared coatings

The $\mathrm{MoO}_{2}$ phase appears in the M70 coating, through the oxidation of $\mathrm{MoSi}_{2}$ following reaction (6). However, $\mathrm{WO}_{2}$ is not found in the W70 coatings due to its narrow stability domain [20]. During the rapid sintering process, as disilicide particles are contained within the borosilicate glass, an environment with low oxygen content is provided for the oxidation of $\mathrm{WSi}_{2}$ and $\mathrm{MoSi} 2$. Therefore, $\mathrm{W}, \mathrm{Mo}, \mathrm{W}_{5} \mathrm{Si}_{3}$ and $\mathrm{Mo}_{5} \mathrm{Si}_{3}$ phases are preferentially formed rather than $\mathrm{WO}_{3}$ or $\mathrm{MoO}_{3}$ following reaction (7) [19, 21], which can effectively suppress the oxidation of $\mathrm{WSi}_{2}$ and $\mathrm{MoSi}_{2}$ with the evaporation of $\mathrm{WO}_{3}$ or $\mathrm{MoO}_{3}$. Cristobalite is formed not only from the oxidation of $\mathrm{WSi}_{2}$ and $\mathrm{MoSi}_{2}$ according to Eqs. (4) - (8), but also from the partial borosilicate glass crystallized during cooling, especially in coatings with higher $\mathrm{MoSi}_{2}$ content. The corresponding Gibbs free energy $\left(\Delta \mathrm{G}^{0}\right)$ under standard conditions of the reactions (4)-(8) at temperatures ranging from $373 \mathrm{~K}$ to $1773 \mathrm{~K}$ were calculated using the Reaction Web module of FactSage software. As shown in Fig. 2, the $\Delta G^{0}$ values for all reactions are negative, indicating that the reactions can proceed spontaneously. This parameter helps to understand formation process of the as-prepared coatings.

$5 / 7(\mathrm{~W} / \mathrm{Mo}) \mathrm{Si}_{2}(\mathrm{~s})+\mathrm{O}_{2}(\mathrm{~g})=1 / 7(\mathrm{~W} / \mathrm{Mo})_{5} \mathrm{Si}_{3}(\mathrm{~s})+$ $\mathrm{SiO}_{2}(\mathrm{~s})(4)$

$1 / 2(\mathrm{~W} / \mathrm{Mo}) \mathrm{Si}_{2}(\mathrm{~s})+\mathrm{O}_{2}(\mathrm{~g})=1 / 2 \mathrm{~W} / \mathrm{Mo}(\mathrm{s})+\mathrm{SiO}_{2}(\mathrm{~s})$ (5)

$1 / 3(\mathrm{~W} / \mathrm{Mo}) \mathrm{Si}_{2}(\mathrm{~s})+\mathrm{O}_{2}(\mathrm{~g})=1 / 3(\mathrm{~W} / \mathrm{Mo}) \mathrm{O}_{2}(\mathrm{~s})+2 / 3$ $\mathrm{SiO}_{2}(\mathrm{~s})(6)$

$2 / 7(\mathrm{~W} / \mathrm{Mo}) \mathrm{Si}_{2}(\mathrm{~s})+\mathrm{O}_{2}(\mathrm{~g})=2 / 7(\mathrm{~W} / \mathrm{Mo}) \mathrm{O}_{3}(\mathrm{~g})+4 / 7$ $\mathrm{SiO}_{2}(\mathrm{~s})(7)$

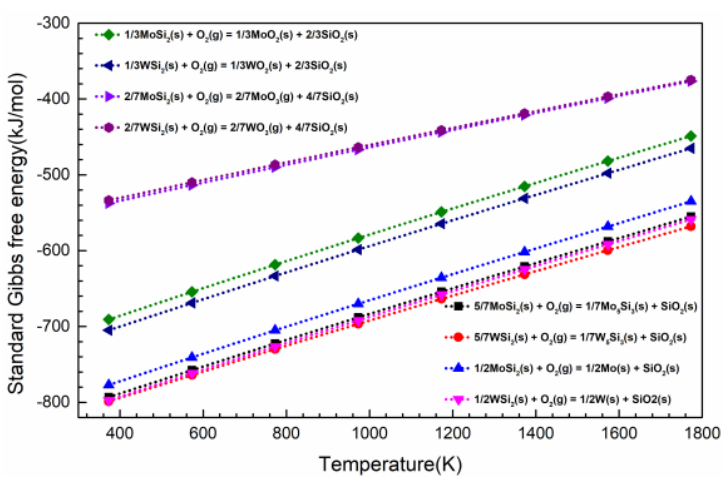

Fig.2 Changes of standard Gibbs free energies of reactions (4)-(7) at different temperatures calculated by the Reaction Web module of FactSage. Cross-sectional SEM micrographs of the as-prepared coating (W20M50), along with the fibrous substrate are shown in Fig. 3. The overall coating thickness is found to be in the order $80-100 \mu \mathrm{m}$. Three distinctive 
Shao, Gaofeng, et al. "Improved oxidation resistance of high emissivity coatings on fibrous ceramic for reusable space systems." Corrosion Science 146 (2019): 233-246.

microstructures observed in the coating are (A) the top layer, (B) the main layer and (C) the interfacial transition layer, which are further magnified in Fig. $3(\mathrm{~b}-\mathrm{d})$.
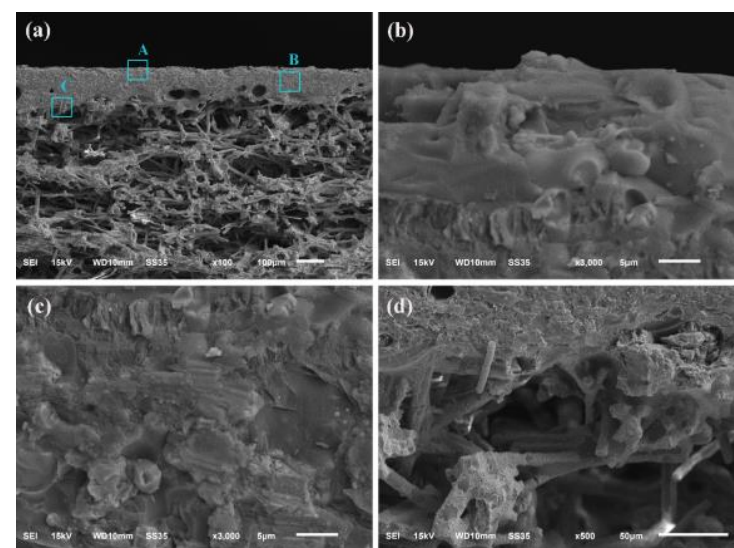

Fig.3 (a) Cross-sectional SEM images of the asprepared coating (W20M50); (b), (c), (d) The magnified SEM images of region $A, B$ and $C$ in (a).

A BSE SEM micrograph of a polished cross-section embedded in resin shows the morphology of the asprepared W20M50 coating in Fig. 4(a), revealing three phases (in addition to the upper and lower resin layers), distinguished by their greyscale levels. Elemental mapping (Fig. 4 (b)-(h)) shows that $\mathrm{MoSi}_{2}$ and $\mathrm{WSi}_{2}$ are surrounded by the borosilicate glass.

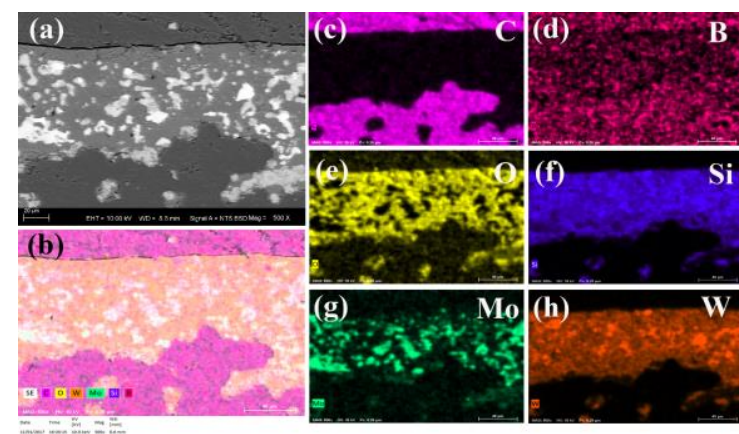

Fig.4 (a) BSE image and (b-h) EDS mappings of the polished cross-section of W20M50

\subsection{Radiative properties of coatings}

In order to investigate the radiative properties of the $\mathrm{WSi}_{2}-\mathrm{MoSi}_{2}$ based coatings after long-term hightemperature oxidation, an isothermal oxidation test at $1773 \mathrm{~K}$ in air was carried out. Fig. 5 compares the spectral emissivity curves of the coatings before and after oxidation at $1773 \mathrm{~K}$ for $50 \mathrm{~h}$ in the wavelength range of $0.3-2.5 \mu \mathrm{m}$ and $2.5-15 \mu \mathrm{m}$.
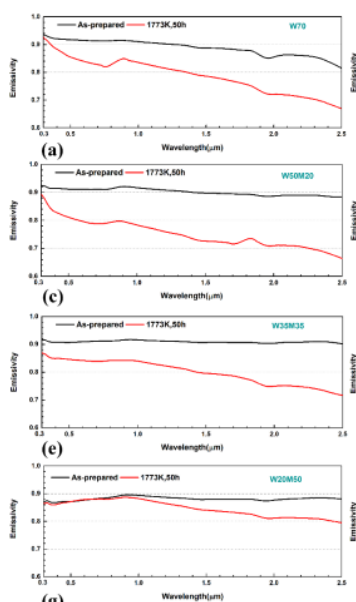

(g)
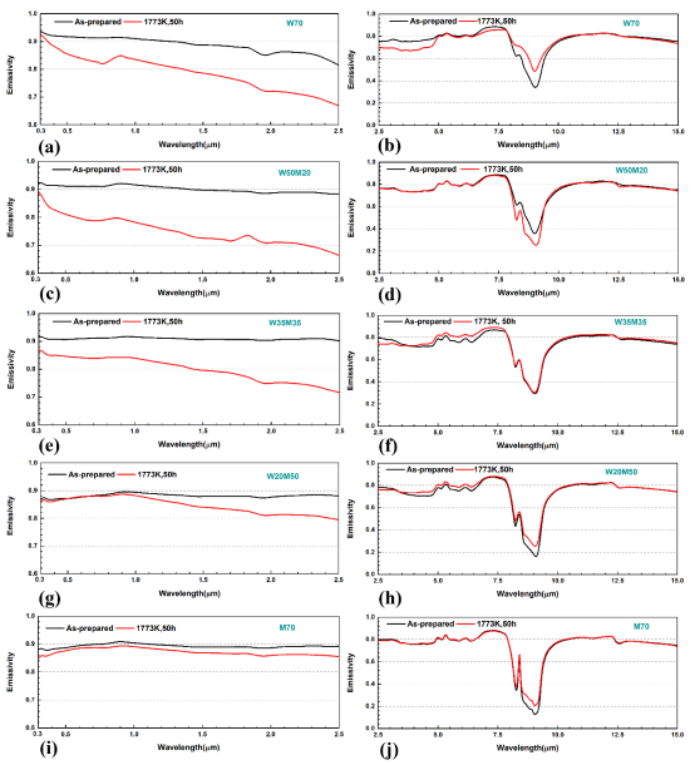

Fig.5 Spectral emissivity curves of coatings before and after oxidation at $1773 \mathrm{~K}$ for $50 \mathrm{~h}$ in the wavelength range of $0.3-2.5 \mu \mathrm{m}$ and $2.5-15 \mu \mathrm{m}$

In the wavelength regime $0.3-2.5 \mu \mathrm{m}$ the spectral emissivity curves of all as-prepared coatings with different compositions present similar features, and emissivity values are above 0.85 . Over the wavelength range of $2.5-15 \mu \mathrm{m}$, emissivity varies in the region of 0.8 with a moderate shoulder around $9 \mu \mathrm{m}$, corresponding to the asymmetrical $\mathrm{Si}-\mathrm{O}$ stretching vibrations of $\left[\mathrm{SiO}_{4}\right]$ tetrahedra. The phenomenon is more prominent the amorphous $\mathrm{SiO}_{2}$-based glass phase rather than the silicide [22-24]. Fig. 6 shows the histogram of the calculated total emissivity at various wavelengths according to Eqs. (1) and (2). For wavelengths in the range $0.3-2.5 \mu \mathrm{m}$, the total emissivity values of the five as-prepared coatings with increasing $\mathrm{MoSi}_{2}$ content are 0.925, 0.915, 0.910, 0.869 and 0.881 . In the wavelength range of 3-5 $\mu \mathrm{m}$, the emissivity values are greater than 0.7 . In contrast, in the range of $8-14 \mu \mathrm{m}$, the emissivity is only $\sim 0.6$. After oxidation at $1773 \mathrm{~K}$ for $50 \mathrm{~h}$, emissivity values of the different $\mathrm{WSi}_{2}-\mathrm{MoSi}_{2}$ based coatings are reduced to varying degrees.

Planck's radiation law given in Eq. (8), shows the spectral emissive power as a function of wavelength 
Shao, Gaofeng, et al. "Improved oxidation resistance of high emissivity coatings on fibrous ceramic for reusable space systems." Corrosion Science 146 (2019): 233-246.

$$
\begin{aligned}
& \text { and temperature. } \\
& E_{\lambda \mathrm{b}}(T)=\frac{2 \pi C_{1}}{n^{2} \lambda^{5}\left[\exp \left(\frac{C_{2}}{n \lambda T}\right)-1\right]}
\end{aligned}
$$

This relationship shows that in general total radiated energy increases at higher temperatures and the intensity peak of the emitted spectrum shifts to shorter wavelengths. Additionally, energy emitted at shorter wavelengths increases more rapidly with temperature than the energy at longer wavelengths. As an example, for an ideal blackbody at $1273 \mathrm{~K}, 97 \%$ of the energy emitted in thermal equilibrium is below $14 \mu \mathrm{m}$, and $76 \%$ is below $5 \mu \mathrm{m}[25]$.

As per Wien's displacement law (9):

$\lambda_{\max }=\frac{b}{T}, b=2.898 \times 10^{-3} \mathrm{mK}$

This equation shows that in general, when the temperature increases from $1673 \mathrm{~K}$ to $2273 \mathrm{~K}$, the largest radiated wavelength shifts from approximately $1.73 \mu \mathrm{m}$ to $1.27 \mu \mathrm{m}$. For W70, W50M20 and W35M35 coatings, the total emissivity values decrease from $0.900,0.900$ and 0.909 to $0.792,0.735$ and 0.803 , respectively, over the wavelength range $1.27-1.73 \mu \mathrm{m}$ (histogram in red).
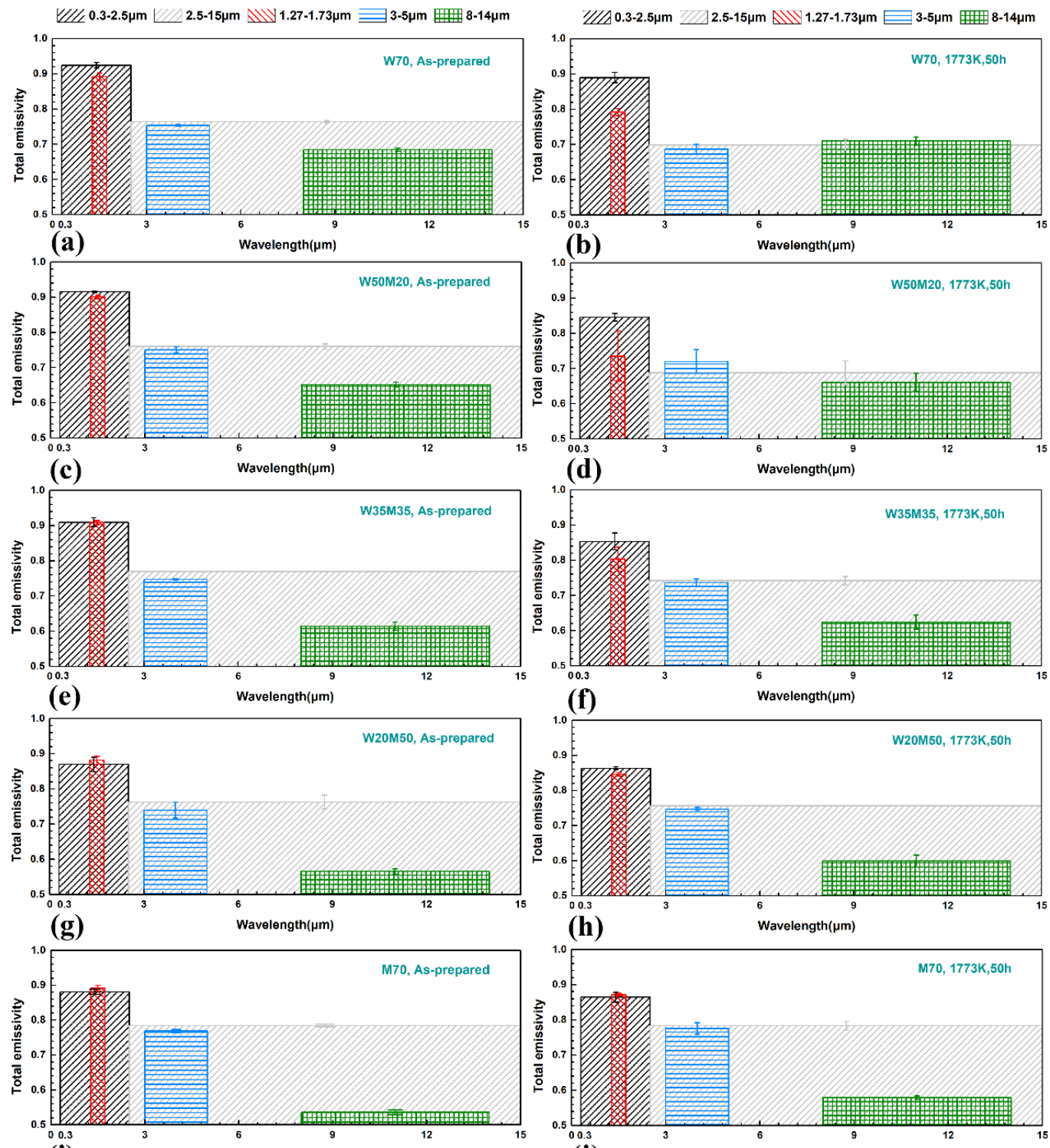

(i)

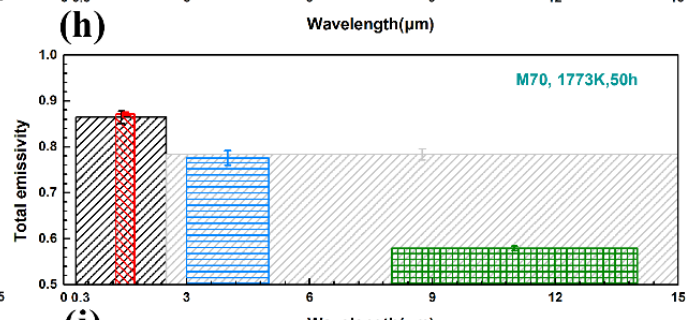

(j)

Fig.6 Histograms of the calculated total emissivity in various wavelengths of the as-prepared coatings before and after oxidation at $1773 \mathrm{~K}$ for $50 \mathrm{~h}$ 
Shao, Gaofeng, et al. "Improved oxidation resistance of high emissivity coatings on fibrous ceramic for reusable space systems." Corrosion Science 146 (2019): 233-246.

However, in the case of W20M50 and M70 coatings, the total emissivity values remain as high as 0.846 and 0.872 with only $4.0 \%$ and $2.1 \%$ decreases in emissivity, respectively. The attenuation of the coatings in $2.5-15$ $\mu \mathrm{m}$ (histogram in grey) gradually decreases with the increase of $\mathrm{MoSi}_{2}$ amount. The radiative loss of W70 coating in this wavelength region reaches to $8.6 \%$, which is much higher than that of M70 coating (0.3\%).

\subsection{Oxidation resistance}

\subsubsection{Isothermal oxidation curves}

Fig.7 shows the isothermal oxidation curves of the coated samples at $1773 \mathrm{~K}$ for $50 \mathrm{~h}$. It can be seen that the oxidation of the samples occurs as a continuous mass loss process. The process can be divided into two stages: the initial fast oxidation stage $(0-10 \mathrm{~h})$ and the slow stable oxidation stage (10-50 h). Neither a linear nor a parabolic rate law can be fitted. The mass loss per unit area of W70, W50M20, W35M35, W20M50 and M70 coatings are $6.70 \mathrm{mg} / \mathrm{cm}^{2}, 7.79 \mathrm{mg} / \mathrm{cm}^{2}, 11.92$ $\mathrm{mg} / \mathrm{cm}^{2}, 10.06 \mathrm{mg} / \mathrm{cm}^{2}$ and $14.96 \mathrm{mg} / \mathrm{cm}^{2}$, respectively. Though the mass loss values of W70 and W50M20 coatings were the lowest, these coatings are not necessarily endowed with the best thermal resistance.

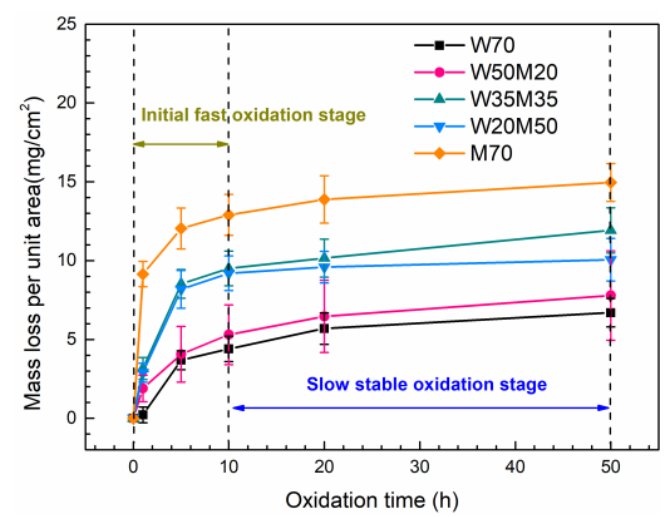

Fig.7 Mass loss per unit area of coated samples during isothermal oxidation at $1773 \mathrm{~K}$ in air.

3.3.2 Phase compositions and chemical states of oxidized coatings

To examine the phase compositions of surfaces, the XRD patterns of the coated samples after oxidation at $1773 \mathrm{~K}$ for $50 \mathrm{~h}$ are shown in Fig. 8. Compared with the original coatings, the intensity of $\mathrm{WSi}_{2}$ and $\mathrm{MoSi}_{2}$ diffraction peaks decrease, and $\mathrm{W}, \mathrm{Mo}, \mathrm{W}_{5} \mathrm{Si}_{3}$ and $\mathrm{Mo}_{5} \mathrm{Si}_{3}$ diffraction peaks become stronger for all coatings.

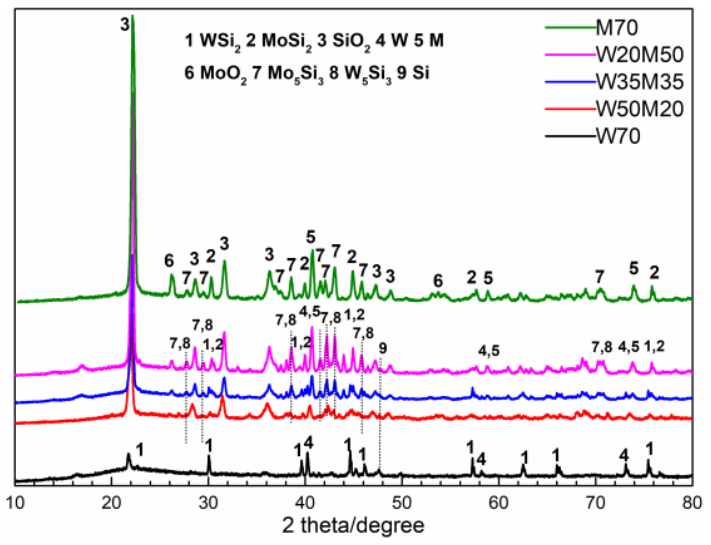

Fig.8 XRD patterns of the different coatings after oxidation at 1773K for $50 \mathrm{~h}$

During the initial fast oxidation stage, the simultaneous oxidation of $\mathrm{W}, \mathrm{Mo}$ and Si takes place according to reactions (7) and (12) [26]. The evaporation of $\mathrm{WO}_{3}$ and $\mathrm{MoO}_{3}$ leads to the rapid mass loss of the coatings. With prolonged oxidation time, a $\mathrm{SiO}_{2}$-based glass compound scale is gradually formed on the outermost layer. This protective layer limits oxygen diffusion and inhibits the further oxidation of the inner coating, resulting in a flattening of the oxidation rate in the slow stable oxidation stage. In an environment with low oxygen pressure only $\mathrm{Si}$ can be oxidized as given in reactions (5) and (10) [27], and the oxidation of $\mathrm{W}$ and Mo could not take place when the coating was entirely covered by dense $\mathrm{SiO}_{2}$-based glass layer [28] According to the calculated standard Gibbs free energies of reactions (10) - (12) in Fig. 9, reactions (11) and (12) is preferred in an excessive oxygen environment, while the preferential oxidation of $\mathrm{Si}$ occurs in an oxygen-lean environment as indicated by reaction (10). It is the reason why $\mathrm{W}$ and Mo phases with strong intensity are detected in the coatings.

$1 / 3(\mathrm{~W} / \mathrm{Mo})_{5} \mathrm{Si}_{3}(\mathrm{~s})+\mathrm{O}_{2}(\mathrm{~g})=5 / 3 \mathrm{~W} / \mathrm{Mo}(\mathrm{s})+\mathrm{SiO}_{2}(\mathrm{~s})(10)$

$2 / 21(\mathrm{~W} / \mathrm{Mo})_{5} \mathrm{Si}_{3}(\mathrm{~s})+\mathrm{O}_{2}(\mathrm{~g})=10 / 21 \quad(\mathrm{~W} / \mathrm{Mo}) \mathrm{O}_{3}$

$(\mathrm{g})+6 / 21 \mathrm{SiO}_{2}(\mathrm{~s})(11)$

$2 / 3(\mathrm{~W} / \mathrm{Mo})+\mathrm{O}_{2}(\mathrm{~g})=2 / 3(\mathrm{~W} / \mathrm{Mo}) \mathrm{O}_{3}(\mathrm{~g})(12)$ 
Shao, Gaofeng, et al. "Improved oxidation resistance of high emissivity coatings on fibrous ceramic for reusable space systems." Corrosion Science 146 (2019): 233-246.

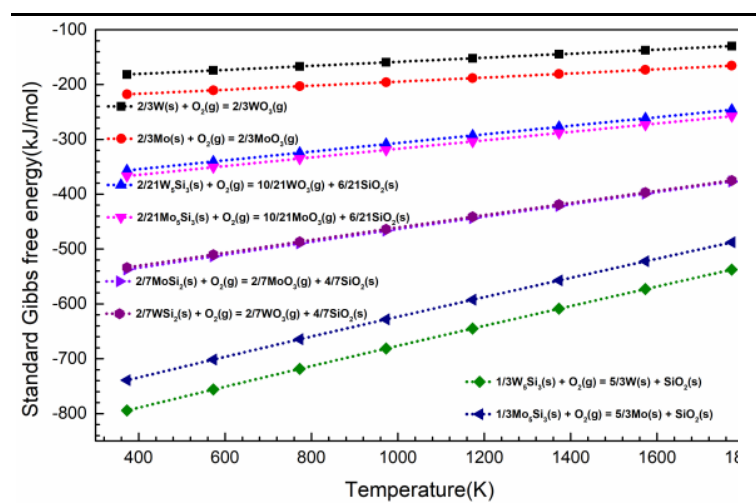

Fig. 9 Changes of standard Gibbs free energies of reactions (7)-(10) at different temperatures calculated by the Reaction Web module of FactSage

The chemical states of the coatings after oxidation are

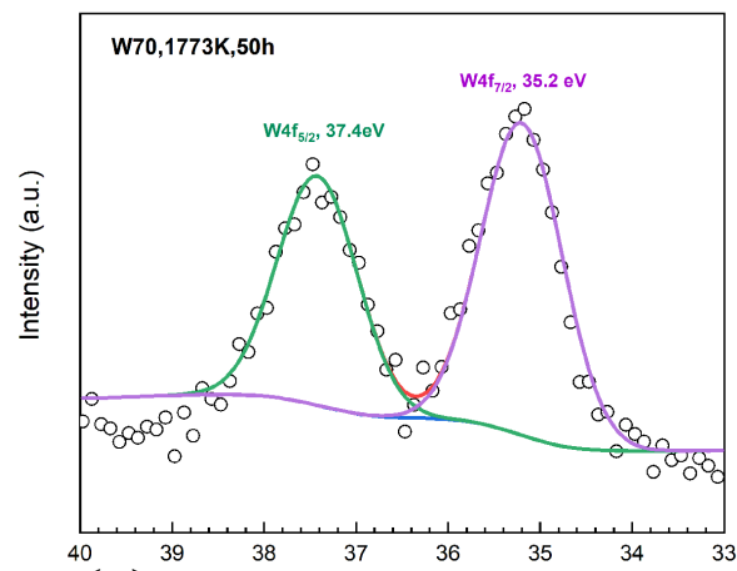

(a)

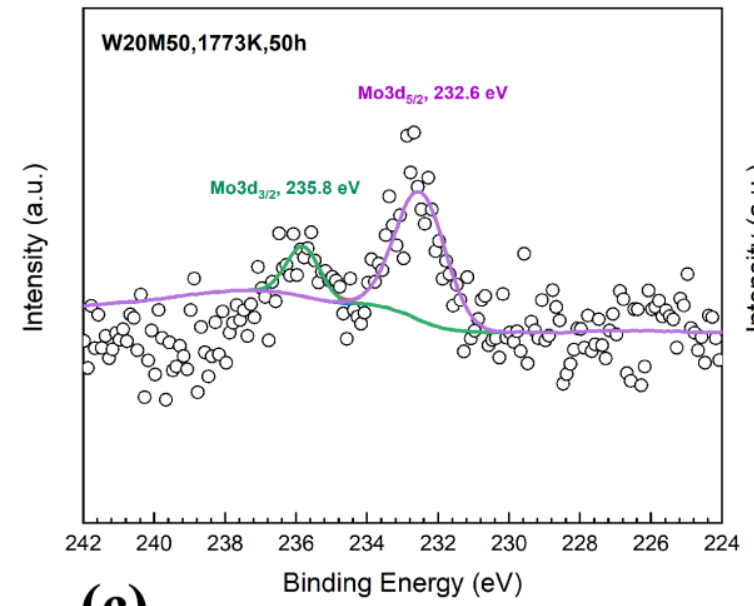

(c) further investigated by XPS, this is particularly useful to interpret changes in the viscosity of the surface glass layer. Fig. 10 shows the high-resolution XPS W4f and Mo3d spectra of the coatings after oxidation. The W4f spectrum was analyzed in W70 and W20M50 coatings, and can be deconvoluted into one doublet. The binding energies of $\mathrm{W}_{4} \mathrm{f}_{5 / 2}$ and $\mathrm{W} 4 \mathrm{f}_{7 / 2}$ are determined to be 37.4 $\mathrm{eV}$ and $35.2 \mathrm{eV}$ in Fig.10 (a) and $37.8 \mathrm{eV}$ and $35.8 \mathrm{eV}$ in Fig. 10 (b), respectively, which is characteristic of $\mathrm{WO}_{3}$ [29]. However, no XPS signals of metallic $\mathrm{W}$ with the binding energies of $\mathrm{W}_{4} \mathrm{f}_{5 / 2}(33.2 \mathrm{eV})$ and $\mathrm{W} 4 \mathrm{f}_{7 / 2}$ $(31.0 \mathrm{eV})$ are detected.
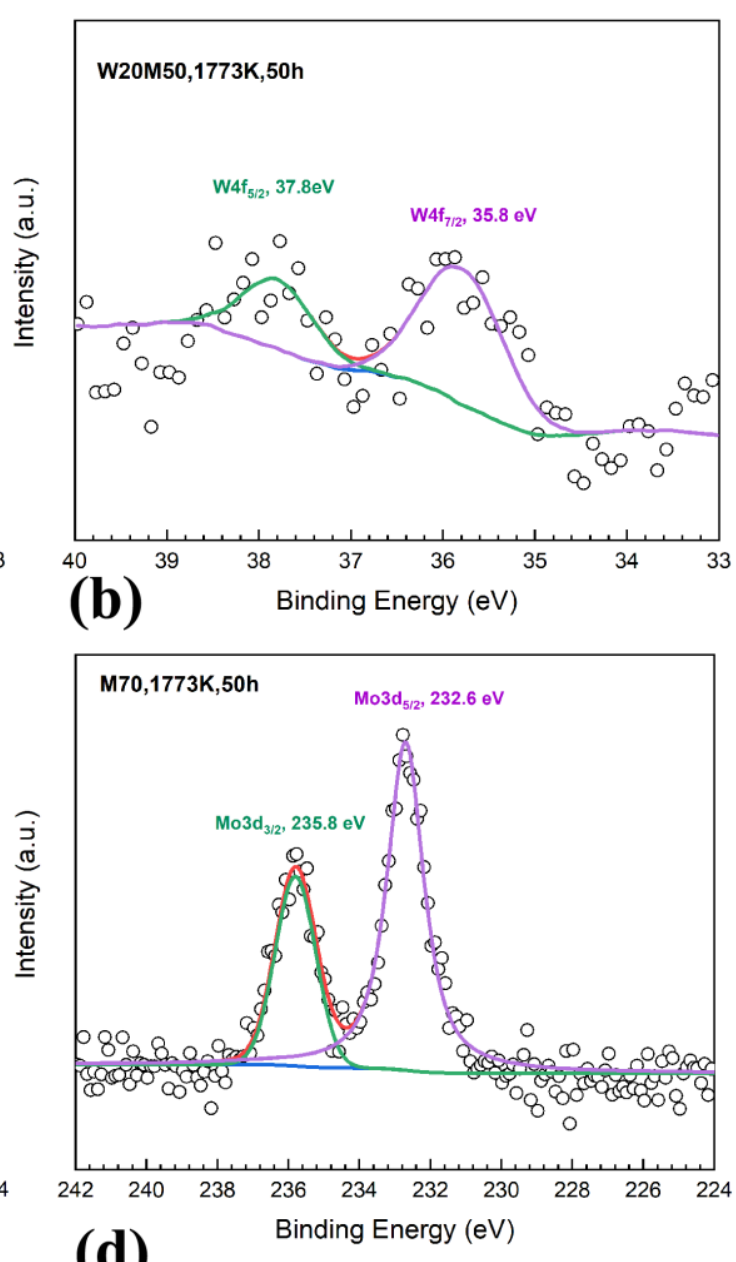

(d)

Fig.10 XPS W4f and Mo3d spectra of the coatings after oxidation at $1773 \mathrm{~K}$ for $50 \mathrm{~h}$, (a) W70; (b-c) W20M50; (d) M70

Fig. 10 (c) and (d) show the high-resolution XPS Mo3d spectra of W20M50 and M70 coatings, and the binding energies of $\mathrm{Mo}_{3 / 2}$ and $\mathrm{Mo}_{3} \mathrm{~d}_{5 / 2}$ are determined to be $235.8 \mathrm{eV}$ and $232.6 \mathrm{eV}$, respectively, consistent with the presence of $\mathrm{MoO}_{3}[29,30]$. No Mo3d $5 / 2$ values of $229.4 \mathrm{eV}$ and $228 \mathrm{eV}$ are obtained, 
Shao, Gaofeng, et al. "Improved oxidation resistance of high emissivity coatings on fibrous ceramic for reusable space systems." Corrosion Science 146 (2019): 233-246.

implying the absence of $\mathrm{Mo}$ and $\mathrm{MoO}_{2}$ phases on the surface of the coatings. However, W, Mo and $\mathrm{MoO}_{2}$ phases were indeed detected by XRD (Fig. 8). This may be the result of the greater X-ray penetration depth, which is generally within tens of micrometers, while the photoelectrons escape depth of the coated sample is approximately a few nanometers. These results suggest that trace amounts of $\mathrm{WO}_{3}$ and $\mathrm{MoO}_{3}$ form at surfaces within depths of a few nanometers according to Eq. (10)-(11), while $\mathrm{W}, \mathrm{Mo}$ and $\mathrm{MoO}_{2}$ are generated in the coatings at depths in the order of tens of micrometers in accordance with Eq. (5), (6) and (10).

Viscosity is one the most important properties for the glass phase generated on the coating surface after high temperature oxidation. To date, only limited studies have been implemented to measure the viscosity of coatings. Previous research confirmed the effectiveness of XPS for directly measuring the relative concentrations of bridging oxygen (BO) and nonbridging oxygen (NBO) in the glass phase [11]. A bridging oxygen atom contains two bonds with energy near $532 \mathrm{eV}$, while non-bridging oxygen atoms occupy a single bond and a partial negative charge resulting in a shift in bond energy to approximately $530 \mathrm{eV}$ [31]. Fig.11 shows the high-resolution XPS O1s spectra of the W70, W20M50 and M50 coatings after oxidation at $1773 \mathrm{~K}$ for $50 \mathrm{~h}$. The binding energy values of BO are determined to be $532.2 \mathrm{eV}, 532.3 \mathrm{eV}$ and $532.3 \mathrm{eV}$, respectively. The NBO contribution of the three coatings is identified at the binding energy of $530.6 \mathrm{eV}$. Furthermore, the relative NBO concentration for these three coatings, corresponding to the area of the NBO peak over the total measured peak area, is $13.67 \%, 9.06 \%$ and $7.47 \%$, respectively. The decrease in NBO concentration with increasing $\mathrm{MoSi}_{2}$ content indicates that the glass viscosity of the coating increases. Based on XRD results, the cristobalite content increases with $\mathrm{MoSi}_{2}$ content. It can be inferred that the crystalline $\mathrm{SiO}_{2}$ incorporated in the oxide scale increases the viscosity of glass layer [32].
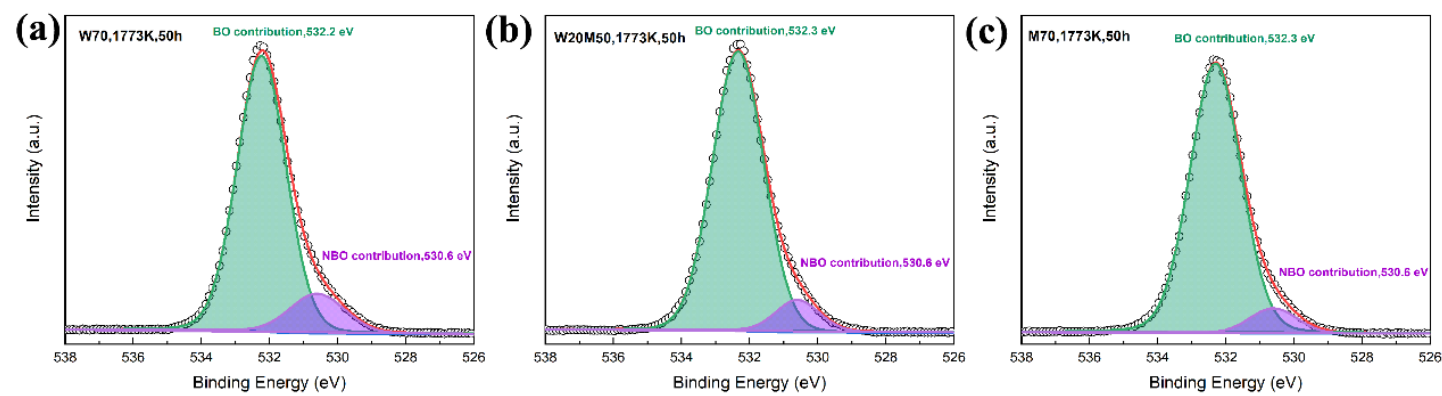

Fig.11 High-resolution XPS O1s spectra of the coatings after oxidation at $1773 \mathrm{~K}$ for $50 \mathrm{~h}$, (a) W70; (b) W20M50; (c) M70

\subsubsection{Microstructure following oxidation}

Fig. $12(a-j)$ show macroscopic images of the entire coated samples, as prepared, as well as following oxidation at $1773 \mathrm{~K}$ for $50 \mathrm{~h}$. As shown in Fig. 12 (a-e), the obtained coatings are dense, smooth and without cracks. However, the coatings exhibit different degrees of damage after long-term oxidation. Several significant cracks are generated on the surface of the W70 coating (Fig.12 (f)). With increasing $\mathrm{MoSi}_{2}$ content, the size and amount of the cracks formed decrease, as seen in W50M20 and W35M35 (Fig. 12(gh)). It is worth noting that no apparent cracks and no yellow phase are observed on the surface of W20M50 (Fig. 12(i)), which suggests that this material retains its structural integrity during oxidation. Relative to the surface of M70 (Fig. 12(j)), the surface of W20M50 is smoother and denser, implying that this sample exhibited optimal glass viscosity in the top layer, which plays a key role in suppressing and sealing the crack itself.

The surface and cross-section CLSM images of the coatings after oxidation are displayed in Fig. 12(k-t). As seen clearly in Fig.12 (p-q), the failure mode of W70 and W50M20 coatings includes delamination between the coating and the substrate, as the result of 
Shao, Gaofeng, et al. "Improved oxidation resistance of high emissivity coatings on fibrous ceramic for reusable space systems." Corrosion Science 146 (2019): 233-246.

\begin{abstract}
differential thermal expansion. When thermally
phase, $\mathrm{WO}_{3}, \mathrm{~W}, \mathrm{~W}_{5} \mathrm{Si}_{3}$ ) [14].

induced stresses exceed the cohesive strength between

Surface SEM images of W70, W20M50 and M70

the coating and the fibrous $\mathrm{ZrO}_{2}$ layers, cracks and coatings after oxidation at $1773 \mathrm{~K}$ for $50 \mathrm{~h}$ are shown delamination occur in the interface. The failure of W70 and W50M20 coatings during high temperature in Fig.13. In M70, further to surface macro-cracks (Fig. oxidation can be predominantly attributed to the 12(f)) and delamination from the substrate (Fig. 12(p)), formation of cracks on the coating surface and delamination between the coating and the substrate. Delamination arises not only as the result of differential thermal expansion between the $\mathrm{WSi}_{2}-\mathrm{Si}_{-}-\mathrm{SiB}_{6}$ borosilicate glass coating and the fibrous $\mathrm{ZrO}_{2}$ substrate, but also from the volumetric swelling micro pores are observed within the glassy phase (Fig. 13(a) and (d)) as the result of gaseous oxides such as $\mathrm{B}_{2} \mathrm{O}_{3}$ and $\mathrm{MoO}_{3}$ escaping from the low viscosity coating surface. As shown in Fig. 13(b) and (e), rather than pores, several nano-cracks are formed on the W20M50 coating surface, resulting from the volume expansion of the top oxidized layer.
\end{abstract}

incurred by the formation of oxidation products (glass
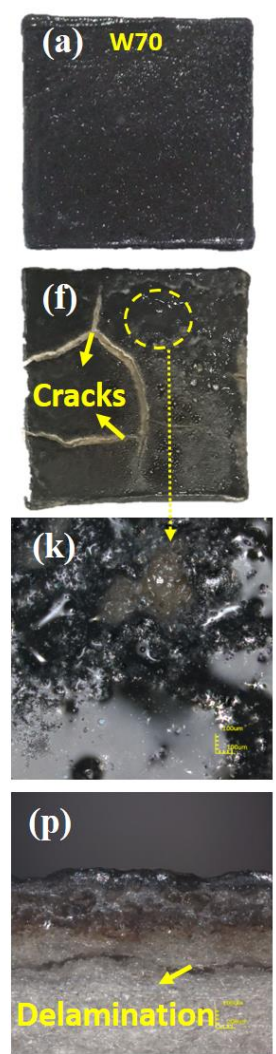
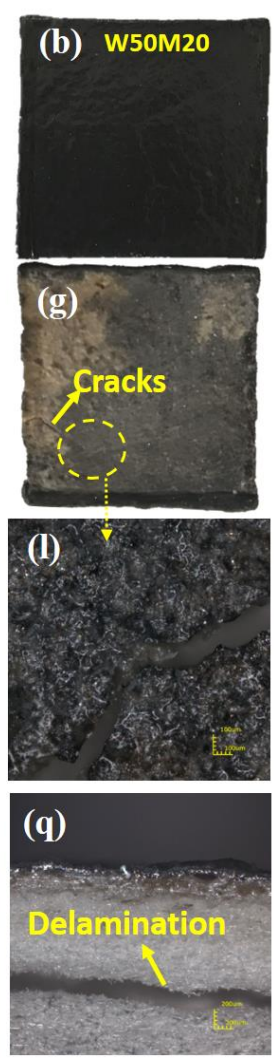
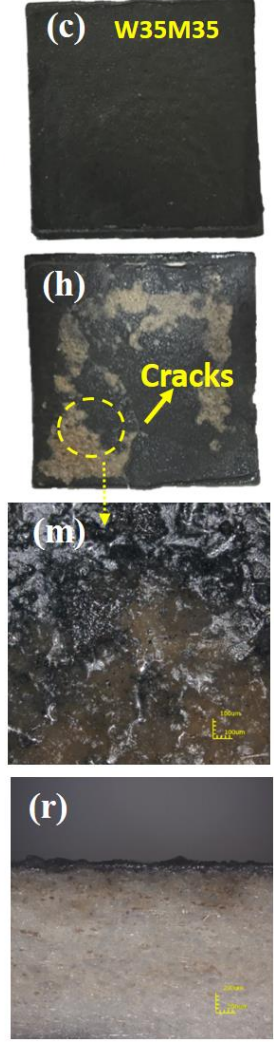
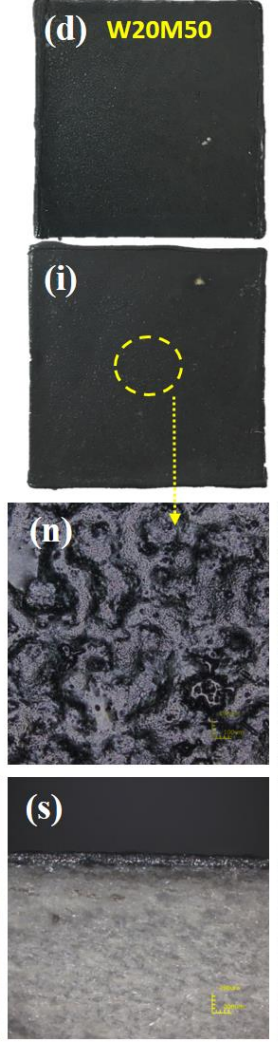
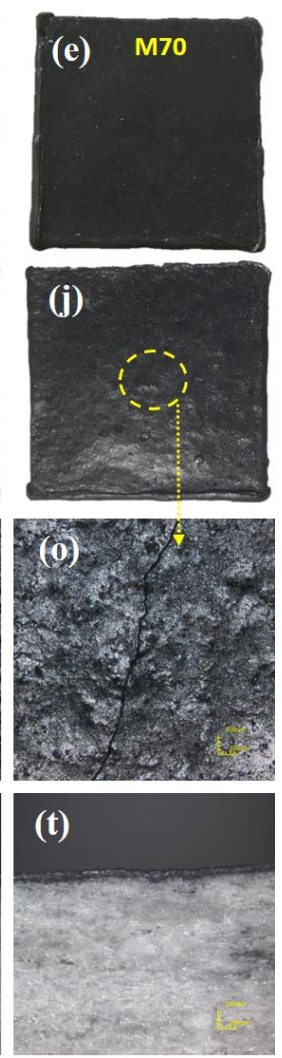

Fig.12 Macrographs of the as-prepared coatings (a-e) and the coatings after oxidation at $1773 \mathrm{~K}$ for $50 \mathrm{~h}$ (f$\mathrm{j}$ ); The surface (k-o) and cross-section (p-t) CLSM images of the coatings after oxidation at $1773 \mathrm{~K}$ for $50 \mathrm{~h}$ 
Shao, Gaofeng, et al. "Improved oxidation resistance of high emissivity coatings on fibrous ceramic for reusable space systems." Corrosion Science 146 (2019): 233-246.
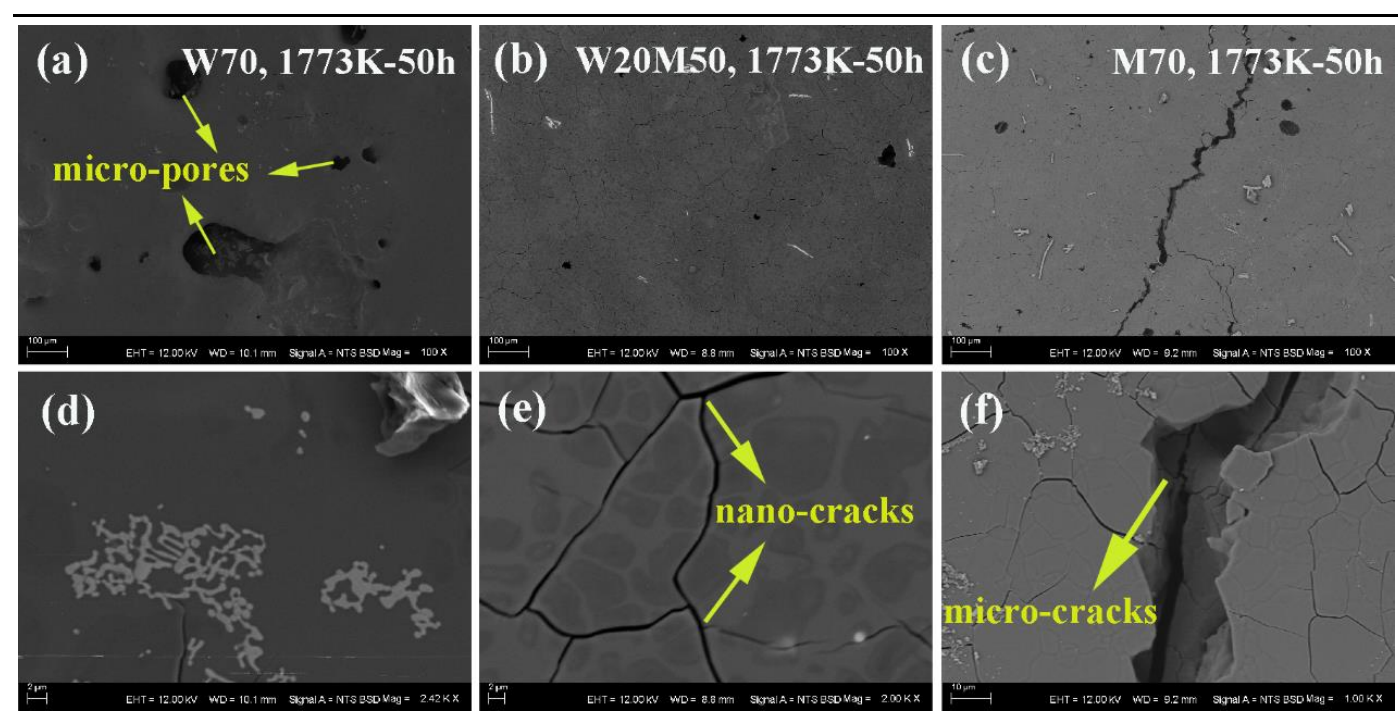

Fig.13 SEM images of coatings after oxidation at $1773 \mathrm{~K}$ for $50 \mathrm{~h}$ in air: W70 (a,d); W20M50 (b,e); M70(c,f)

Similarly, in M70 a deep micro-crack and some nanosized cracks are evident (Fig. 13(f)) and are attributed to the high viscosity of the top $\mathrm{SiO}_{2}$-rich glass layer which limits its ability to seal cracks. The BSE image of Fig. 14 shows the polished cross-section morphology and the corresponding elemental mapping of the W20M50 coating after oxidation. Though some surface nano-cracks are observed, no vertical cracks are evident for this composition.

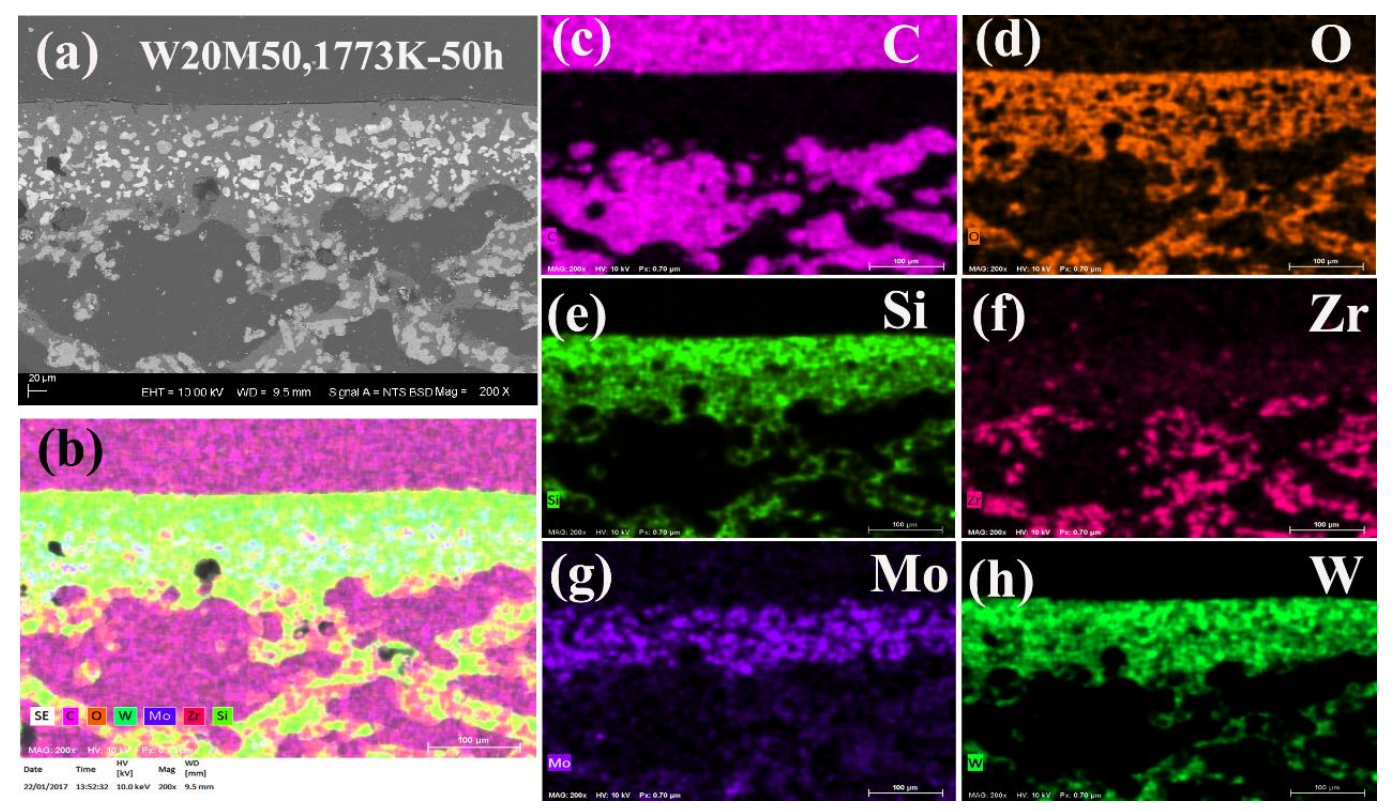

Fig.14 (a) BSE image and (b-h) EDS mappings of the polished cross-section of W20M50 after oxidation at $1773 \mathrm{~K}$ for $50 \mathrm{~h}$

\section{Discussion}

\subsection{Comparative performance}

Towards applications in thermal protection systems, various silicide materials for oxidation resistant and high emissivity coatings have been investigated [3336]. Systems studied thus far include YSZ-La-Mo-Si,
MoSi2-WSi2-SiC-Si and TaSi2-MoSi2 with borosilicate glass. However, materials investigated to date have been limited in terms of their high temperature oxidation resistance. Following long-term high temperature treatment at temperatures similar to those employed in the present work, oxide phases, such as 
Shao, Gaofeng, et al. "Improved oxidation resistance of high emissivity coatings on fibrous ceramic for reusable space systems." Corrosion Science 146 (2019): 233-246.

$\mathrm{SiO}_{2}$ or $\mathrm{Ta}_{2} \mathrm{O}_{5}$, are ubiquitously observed to form on the surfaces of these materials, while diffraction peaks corresponding to the emissive agents are subsequently absent. The formation of oxidized phases and the consumption of the emissive phases limits the utility of such coatings for HEC applications.

In our previous work, $\mathrm{WSi}_{2}$ was confirmed as a high emissivity material in theory by first principle calculations. Then a novel $\mathrm{WSi}_{2}$-Si-glass coating using $\mathrm{WSi}_{2}$ as an emissive agent was fabricated. However, after oxidation at $1773 \mathrm{~K}$ for $20 \mathrm{~h}$, the emissivity dramatically declined and the coating was destroyed [14]. In order to improve the thermal resistance of the coating, $\mathrm{WSi}_{2}$ and $\mathrm{MoSi}_{2}$ were combined as double phase emissive agents in this work. Of the compositions studied, W20M50 exhibited the most promising performance. Diffraction patterns show that the emissive phases $\mathrm{WSi}_{2}$ and $\mathrm{MoSi}_{2}$ were still present in the surface of this coating following oxidation at $1773 \mathrm{~K}$ for $50 \mathrm{~h}$, which is ascribed to the low oxygen diffusion rate of the $\mathrm{SiO}_{2}$-based glass compound in the outmost layer and the self-healing ability of the inner layer of the coating over a wide temperature range. Based on the analysis of XRD, XPS and morphology results, it can be inferred that the thermal stability and appropriate viscosity of the top glass layer and the good self-healing ability of W20M50 help maintain the emissivity of the coating under a high temperature oxidizing atmosphere.

\subsection{Oxidation mechanism}

In general, the oxidation process consists of two stages: the initial fast oxidation stage, accompanied by significant defect formation and the second, slow stable oxidation stage, which is accompanied by defect healing. There are two sources of thermal stress in the coating during the oxidation process: (i) differential thermal expansion between the coating and the substrate (ii) aging stress between the newly formed surface oxide layer and inner coating layer. Thermal stress induced defects including cracks, spallation and delamination are observed to varying extents in all coatings, directly affecting the radiative property of the coatings after long-term high temperature oxidation. A further defect: micro pores, arise as the result of the volatilization of $\mathrm{B}_{2} \mathrm{O}_{3}, \mathrm{WO}_{3}$ and $\mathrm{MoO}_{3}$.

\subsubsection{Defect formation}

Firstly, the magnitude of the thermal stress arising from differential thermal expansion can be calculated by Eq. (13)[33]:

$\delta=\frac{E \cdot \Delta \alpha \cdot \Delta T}{1-v}$

in which $E$ is the elastic modulus, $\Delta \alpha$ is the difference between the coefficients of thermal expansion, $\Delta T$ refers to the temperature change and $v$ is Poisson's ratio. Differential thermal expansion between the fibrous $\mathrm{ZrO}_{2}$ substrate $\left(\alpha=10.2 \times 10^{-6} / \mathrm{K}[10]\right)$ and $\mathrm{WSi}_{2}$ and $\mathrm{MoSi}_{2}$ based coatings ( $\mathrm{MoSi}_{2}: \alpha=9.32 \times 10^{-6} / \mathrm{K}[10]$; WSi2: $\left.\alpha=8.5 \times 10^{-6} / \mathrm{K}[26]\right)$ is responsible for crack formation, particularly during the rapid cooling and heating stages. For the W70 coating, the larger $\Delta \alpha$ induces higher thermal stress relative to M70. Stress concentration at the interface with the substrate causes macro cracks and delamination, which are therefore observed more extensively in W70 (Fig. 12(f) and (p)). Secondly, according to the Pilling-Bedworth theory[37], the magnitude of the aging stress of the coating, which arises as the result of oxidative swelling, can be predicted using Pilling-Bedworth ratio (PBR), and the formula is:

$\mathrm{PBR}=\frac{V_{\text {oxide scale }}}{V_{\text {coating }}}$

where $V$ represents the molar volume. For the oxidation of $\mathrm{MoSi}_{2}$, the calculated PBR values for the formation of $\mathrm{Mo}, \mathrm{MoO}_{2}, \mathrm{MoO}_{3}$ and $\mathrm{Mo}_{5} \mathrm{Si}_{3}$, are 2.51, 2.94, 3.38 and 1.68 , respectively [11]. Correspondingly, the calculated PBR values for the formation of $\mathrm{W}, \mathrm{WO}_{3}$ and $\mathrm{W}_{5} \mathrm{Si}_{3}$ products resulting from the oxidation of $\mathrm{WSi}_{2}$ are 2.4, 3.27 and 1.96, respectively [14]. PBR > 1 , corresponds to swelling, and compressive stress in the oxide scale, while tensile stress develops in scales with $\operatorname{PBR}<1$ [37]. Due to oxidative swelling, scales on $\mathrm{WSi}_{2}-\mathrm{MoSi}_{2}$-Si-glass coatings are in a state of compression irrespective of the oxidation route, and once sufficient coating stress is accumulated, cracks emerge on the coating surface. Accordingly, oxygen penetrates into the coatings through the 
Shao, Gaofeng, et al. "Improved oxidation resistance of high emissivity coatings on fibrous ceramic for reusable space systems." Corrosion Science 146 (2019): 233-246.

aforementioned cracks and reacts with $\mathrm{WSi}_{2}, \mathrm{~W}_{5} \mathrm{Si}_{3}, \mathrm{~W}$, $\mathrm{MoSi}_{2}, \mathrm{Mo}_{5} \mathrm{Si}_{3}$ and Mo according to reactions (7), (10)(12) to form volatile $\mathrm{WO}_{3}$ and $\mathrm{MoO}_{3}$, which escape the coatings through these cracks leading to a continuous weight loss during the initial fast oxidation stage. To better understand the volatilization of $\mathrm{MoO}_{3}$ and $\mathrm{WO}_{3}$, the vapor pressures of the volatile oxides, which form as trimers $\left(\mathrm{MoO}_{3}\right)_{3}$ and $\left(\mathrm{WO}_{3}\right)_{3}$, were calculated by FactSage software and are plotted as a function of temperature

(Fig.

$15)$.

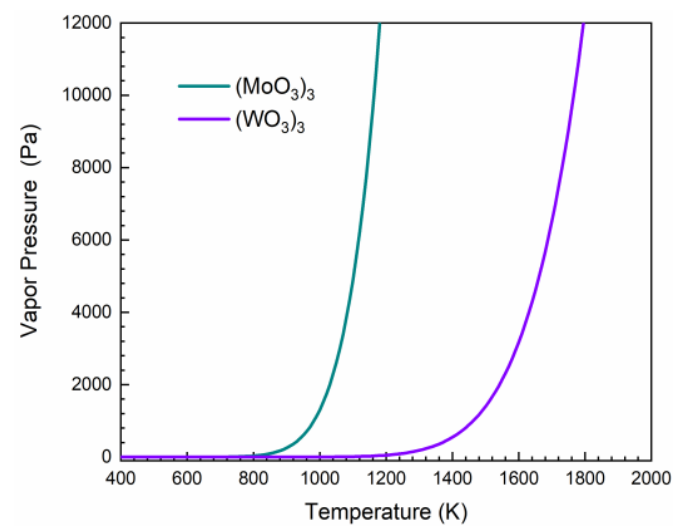

Fig.15 Vapor pressure of $\left(\mathrm{MoO}_{3}\right)_{3}$ and $\left(\mathrm{WO}_{3}\right)_{3}$

As the oxidation temperature increases, "pesting" initially starts at $\sim 773 \mathrm{~K}$ [38-40], with the volatilization of $\mathrm{MoO}_{3}$ in the form of $\left(\mathrm{MoO}_{3}\right)_{3}$. The evaporation of $\mathrm{MoO}_{3}$ takes precedence over $\mathrm{WO}_{3}$. In the intermediate temperature range (1073-1273 K), the evaporation and formation of $\left(\mathrm{MoO}_{3}\right)_{3}$ occur simultaneously while $\mathrm{WO}_{3}$ still remain on the surface due to the low vapor pressure[41]. As the temperature increases further ( $1473 \mathrm{~K})$, the vapor pressure of $\left(\mathrm{WO}_{3}\right)_{3}$ increases, resulting in volatilization of both $\left(\mathrm{MoO}_{3}\right)_{3}$ and $\left(\mathrm{WO}_{3}\right)_{3}$.

\subsubsection{Defect healing}

Owing to the formation of flowable molten phases dispersed within the coatings at high temperatures, defects can be healed to a certain extent at various temperatures. $\mathrm{SiO}_{2}$ and $\mathrm{B}_{2} \mathrm{O}_{3}$, the oxidation products of $\mathrm{SiB}_{6}$ around $840-1240 \mathrm{~K}$, will react to form a borosilicate glass, which can promote the densification of the coating during rapid sintering and seal the defects during long-term oxidation at relatively low temperatures. Another sintering additive, $\mathrm{Si}$, can consume oxygen, thus further inhibiting the oxidation of $\mathrm{WSi}_{2}$ and $\mathrm{MoSi}_{2}$. Meanwhile, molten $\mathrm{Si}$ can seal micro cracks at high temperatures. The self-healing ability of coatings is determined not only by the amount of borosilicate glass but also its viscosity [42]. Yan et al. [43] correlated the viscosity of borosilicate glasses with temperature and boron content, as described in equation

$\log \eta=3.11-19.2 \exp (-24 x)+\frac{1.68 \times 10^{4}}{T}+\frac{4.56 \times 10^{4} \exp (-22 x)}{T}$

. Viscosity is plotted as a function of temperature in Fig.16. Viscosity decreases with increasing boron content, especially at levels under $10 \mathrm{~mol} \% \mathrm{~B}_{2} \mathrm{O}_{3}$. As the temperature increases to $1673 \mathrm{~K}, \mathrm{~B}_{2} \mathrm{O}_{3}$ evaporates and escapes from the borosilicate glass, leading to an increased viscosity of the surface glass layer. Compared with the rapid evaporation of $\mathrm{MoO}_{3}$, the relatively slower evaporation of $\mathrm{WO}_{3}$ is expected to allow sufficient time for borosilicate glass scale to flow and seal the surface[44]Based on the XPS analysis of $\mathrm{O} 1 \mathrm{~s}$, the NBO concentration of W70 is the highest among W70, W20M50 and M70 coatings (Fig. 11(a)), implying lower viscosity.

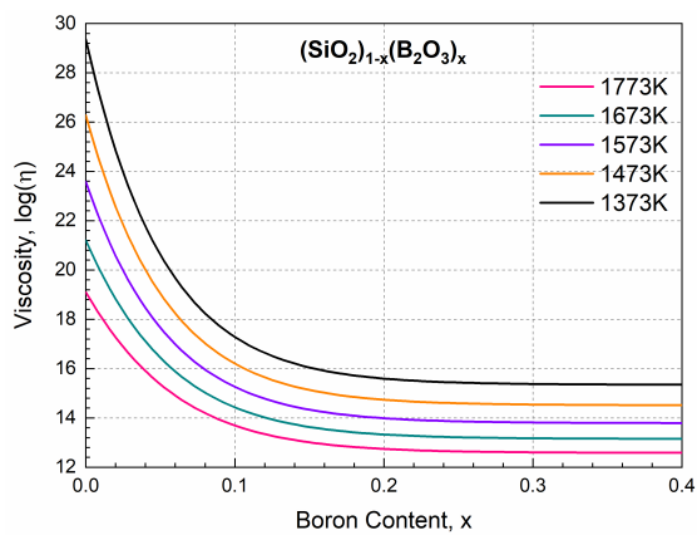

Fig.16 The viscosity of borosilicate as a function of boron content

The borosilicate glass in this material flows more readily and can effectively seal cracks (Fig. 13(a) and (d)). However, this material exhibits the lowest coefficient of thermal expansion as the result of lower glass phase viscosity and high $\mathrm{WSi}_{2}$ content, with the resultant high thermal stresses inducing macroscopic cracks and delamination (Fig. 12(f) and (p)). In contrast, M70, which does not contains $\mathrm{W}$ phases, exhibits lower thermal stresses as the result of higher thermal 
Shao, Gaofeng, et al. "Improved oxidation resistance of high emissivity coatings on fibrous ceramic for reusable space systems." Corrosion Science 146 (2019): 233-246.

expansion, and is more compatible with the substrate material. In M70, with the evaporation of $\mathrm{MoO}_{3}$ and $\mathrm{B}_{2} \mathrm{O}_{3}$, increasing amounts of cristobalite are formed on coating surfaces as confirmed by XRD results (Fig.8), and the NBO concentration in M70 decreases to $7.47 \%$ after oxidation for 50h (Fig.11(c)). The lower fluidity of borosilicate glass with higher $\mathrm{SiO}_{2}$ content limits effective crack sealing in this material (Fig. 12(o) and Fig. 13(c)), resulting in micro-sized cracks (Fig. 13(f)). Achieving optimal self-healing functionality necessitates a balance between glass phase viscosity at high temperatures and reduced thermal stresses at the coating interface. Combining $\mathrm{WSi}_{2}$ and $\mathrm{MoSi}_{2}$ as double phase emissive agents yields suitable viscosity for crack healing while maintaining acceptable levels of differential thermal expansion, thereby improving thermal oxidation resistance of coatings. Consequently, in the W20M50 material only nanoscale cracks were observed on the coating surface (Fig. 13(e)).

\subsection{Summarized advantages of combined tungsten and molybdenum disilicides}

Fig. 17 shows a brief schematic of the oxidation processes of the $\mathrm{WSi}_{2}-\mathrm{MoSi}_{2}$ based coatings according to the above analysis. In the initial fast oxidation stage, cracks are formed on the surfaces of coatings as the result of differential thermal expansion and aging stress. The volatilization of oxides like $\mathrm{MoO}_{3}, \mathrm{WO}_{3}$ and $\mathrm{B}_{2} \mathrm{O}_{3}$ leads to rapid mass loss. In parallel, oxidation reactions result in the formation of a passivating glass scale at the coating surface, which plays an important role in limiting further oxidation induced damage during the slow stable oxidation stage. The different viscosities of the surface glass layers result in different failure behaviors of the coatings.

\section{Initial fast oxidation stage}

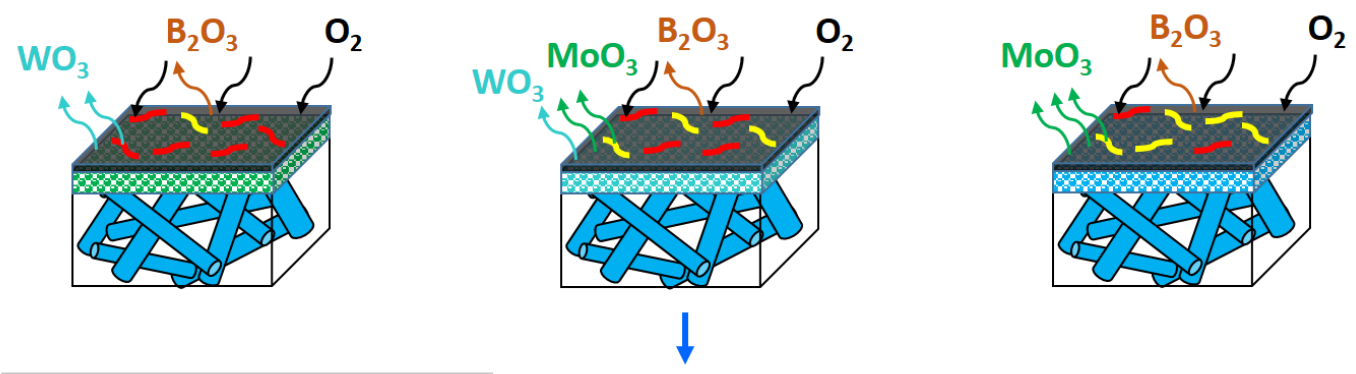

\section{Slow stable oxidation stage}

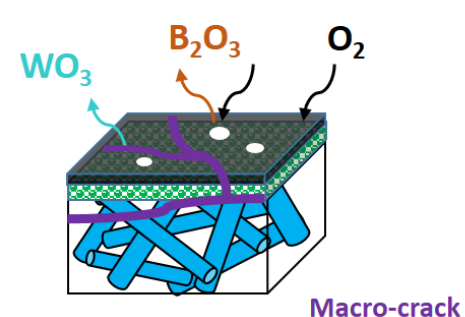

$\mathrm{WSi}_{2}-\mathrm{Si}_{-}-\mathrm{SiB}_{6}$-borosilicate glass coating

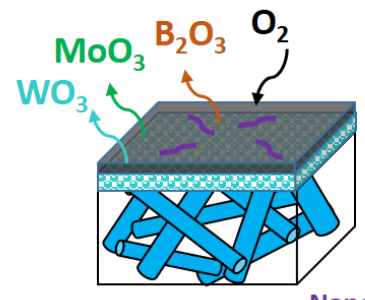

Nano-crack

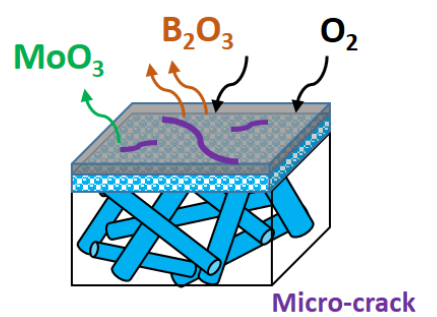

$\mathrm{MoSi}_{2}-\mathrm{Si}_{-} \mathrm{SiB}_{6}$-borosilicate glass coating

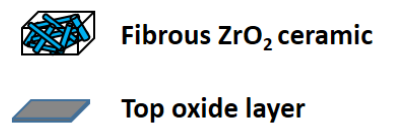

$\mathrm{WSi}_{2}-\mathrm{MoSi}_{2}-\mathrm{Si}-\mathrm{SiB}_{6}$-borosilicate glass coating

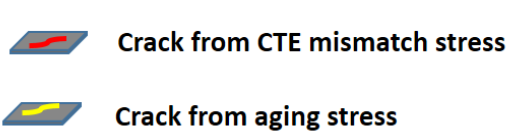

Finial form of crack

Pores

Fig.17 Schematic oxidation processes of coated materials

Although the glass layer in W70 exhibits a low viscosity and can more effectively seal mirco-cracks, the larger thermal stresses between the coating and the substrate leads to the formation of macro-cracks and delamination. In contrast, the M70 coating, with higher viscosity and worse fluidity cannot sufficiently seal the cracks, resulting in micro-cracks. Relative to coatings with only a single silicide phase, the advantages of double phase metal disilicides (combined $\mathrm{WSi}_{2}$ and $\mathrm{MoSi}_{2}$ ) include (1) better thermal expansion 
Shao, Gaofeng, et al. "Improved oxidation resistance of high emissivity coatings on fibrous ceramic for reusable space systems." Corrosion Science 146 (2019): 233-246.

compatibility between the coating and the fibrous $\mathrm{ZrO}_{2}$ substrate, and consequently less defect formation; (2) improved self-healing ability as the result of the oxidation product $\mathrm{WO}_{3}$ limiting the evaporation of $\mathrm{MoO}_{3}$, providing sufficient time for borosilicate glass scale flow, and the appropriate viscosity of the surface glass layer. Accordingly, coatings with both $\mathrm{WSi}_{2}$ and $\mathrm{MoSi}_{2}$ phases exhibited improved oxidation resistance and thermally robust emissivity under a high temperature oxidizing atmosphere, with highest performance levels found in W20M50 materials in the present work. Further compositional optimization and thermal resistance at higher temperatures and dynamic conditions where ablation is significant, remain ripe for further investigation.

\section{Conclusion}

(1) High emissivity multiphase coatings based on different compositions of $\mathrm{WSi}_{2}, \mathrm{MoSi}_{2}, \mathrm{Si}, \mathrm{SiB}_{6}$ and borosilicate glass have been prepared on fibrous $\mathrm{ZrO}_{2}$ by slurry dipping and a subsequent high temperature rapid sintering method. $\mathrm{MoSi}_{2}$ and $\mathrm{WSi}_{2}$ particles are dispersed in the continuous borosilicate glass in the coatings. The presence of a glass layer limits oxygen diffusion and results in the formation of thermally stable $\mathrm{W}, \mathrm{Mo}, \mathrm{W}_{5} \mathrm{Si}_{3}$ and $\mathrm{Mo}_{5} \mathrm{Si}_{3}$ phases from the oxidation of disilicide phases on the surface of the coating.

\section{References}

[1] S. Chiu, W. Pitts, Reusable surface insulations for reentry spacecraft, in: 29th Aerospace Sciences Meeting, American Institute of Aeronautics and Astronautics, 1991.

[2] J. Sun, Z. Hu, J. Li, H. Zhang, C. Sun, Thermal and mechanical properties of fibrous zirconia ceramics with ultra-high porosity, Ceramics International, 40 (2014) 11787-11793.

[3] D.B. Leiser, R. Churchward, V. Katvala, D. Stewart, A. Balter, Advanced Porous Coating for Low-Density Ceramic Insulation Materials, Journal of the American Ceramic Society, 72 (1989) 1003-1010.

[4] M. Wang, X. Li, D. Su, H. Ji, H. Tang, Z. Zhao, J. $\mathrm{He}$, Effect of glass phase content on structure and
(2) Of the compositions studies W20M50, comprising $20 \mathrm{wt} \% \mathrm{WSi}_{2}$ and $50 \mathrm{wt} \% \mathrm{MoSi}_{2}$, presents the highest oxidation resistance, with only $10.06 \mathrm{mg} / \mathrm{cm}^{2}$ mass loss and $4.0 \%$ radiative loss in the wavelength regime $1.27-1.73 \mu \mathrm{m}$ after oxidation at $1773 \mathrm{~K}$ for $50 \mathrm{~h}$. In this material, defect formation was observed to occur during the initial fast oxidation stage, while defect healing occurred during the slow stable oxidation.

(3) The advantages of double phase metal silicides ( $\mathrm{WSi}_{2}$ and $\mathrm{MoSi}_{2}$ ) include (i) better thermal compatibility with the substrate and (ii) appropriate viscosity of the surface glass layer combined with sufficient defect sealing time.

\section{Acknowledgment}

This work was financially supported by the Program for Changjiang Scholars and Innovative Research Team in University (No. IRT_15R35), the National Natural Science Foundation of China (No.51602151), the Natural Science Foundation of Jiangsu Province (No.BK20161003), the Major Program of Natural Science Fund in Colleges and Universities of Jiangsu Province (No.15KJA430005), Priority Academic Program Development of Jiangsu Higher Education Institutions (PAPD), China Scholarship Council (CSC, 201608320159).

properties of gradient $\mathrm{MoSi} 2-\mathrm{BaO}-\mathrm{A} 12 \mathrm{O} 3-\mathrm{SiO} 2$ coating for porous fibrous insulations, Journal of Alloys and Compounds, 657 (2016) 684-690.

[5] Y. Wang, D. Su, H. Ji, X. Li, Z. Zhao, H. Tang, Gradient structure high emissivity MoSi2-SiO2-SiOC coating for thermal protective application, Journal of Alloys and Compounds, 703 (2017) 437-447.

[6] X. Tao, X. Xu, L. Guo, W. Hong, A. Guo, F. Hou, J. Liu, MoSi2-borosilicate glass coating on fibrous ceramics prepared by in-situ reaction method for infrared radiation, Materials \& Design, 103 (2016) 144-151.

[7] X. Tao, X. Li, L. Guo, X. Xu, A. Guo, F. Hou, J. Liu, Effect of TaSi2 content on the structure and properties of TaSi2-MoSi2-borosilicate glass coating on fibrous 
Shao, Gaofeng, et al. "Improved oxidation resistance of high emissivity coatings on fibrous ceramic for reusable space systems." Corrosion Science 146 (2019): 233-246.

insulations for enhanced surficial thermal radiation, Surface and Coatings Technology, 316 (2017) 122-130. [8] G. Shao, X. Wu, Y. Kong, S. Cui, X. Shen, C. Jiao, J. Jiao, Thermal shock behavior and infrared radiation property of integrative insulations consisting of MoSi2/borosilicate glass coating and fibrous $\mathrm{ZrO} 2$ ceramic substrate, Surface and Coatings Technology, 270 (2015) 154-163.

[9] G. Shao, X. Wu, S. Cui, X. Shen, Y. Kong, Y. Lu, C. Jiao, J. Jiao, High emissivity MoSi2-ZrO2borosilicate glass multiphase coating with SiB6 addition for fibrous $\mathrm{ZrO} 2$ ceramic, Ceramics International, 42 (2016) 8140-8150.

[10] G. Shao, X. Wu, S. Cui, X. Shen, Y. Lu, Q. Zhang, Y. Kong, High emissivity MoSi2-TaSi2-borosilicate glass porous coating for fibrous $\mathrm{ZrO} 2$ ceramic by a rapid sintering method, Journal of Alloys and Compounds, 690 (2017) 63-71.

[11] G. Shao, Q. Wang, X. Wu, C. Jiao, S. Cui, Y. Kong, J. Jiao, X. Shen, Evolution of microstructure and radiative property of metal silicide-glass hybrid coating for fibrous $\mathrm{ZrO} 2$ ceramic during high temperature oxidizing atmosphere, Corrosion Science, 126 (2017) 78-93.

[12] L. Charpentier, M. Balat-Pichelin, J.-L. Sans, D. Sciti, L. Silvestroni, Effect of high temperature oxidation on the radiative properties of HfC-based ceramics, Corrosion Science, 126 (2017) 255-264.

[13] A.E. Brenner, A.A. Peña, X.L. Phuah, C. Petorak, B. Thompson, R.W. Trice, Cyclic ablation of highemissivity Sm-doped $\mathrm{ZrB} 2 / \mathrm{SiC}$ coatings on alumina substrates, Journal of the European Ceramic Society, 38 (2018) 1136-1142.

[14] G. Shao, X. Wu, S. Cui, J. Jiao, X. Shen, Design, formation, and property of high emissivity WSi2-Siglass hybrid coating on fibrous $\mathrm{ZrO} 2$ ceramic for reusable thermal protection system, Solar Energy Materials and Solar Cells, 172 (2017) 301-313.

[15] Z. Cai, X. Zhao, D. Zhang, Y. Wu, J. Wen, G. Tian,

Q. Cao, X. Tang, L. Xiao, S. Liu, Microstructure and oxidation resistance of a YSZ modified silicide coating for Ta-W alloy at $1800{ }^{\circ} \mathrm{C}$, Corrosion Science, 143 (2018) 116-128.

[16] Z. Cai, Y. Wu, H. Liu, G. Tian, R. Pu, S. Piao, X.
Tang, S. Liu, X. Zhao, L. Xiao, Formation and oxidation resistance of a new YSZ modified silicide coating on Mo-based alloy, Materials \& Design, 155 (2018) 463-474.

[17] X. Tao, X. Xu, X. Xu, W. Hong, A. Guo, F. Hou, J. Liu, Self-healing behavior in MoSi2/borosilicate glass composite, Journal of the European Ceramic Society, 37 (2017) 871-875.

[18] L. Zhang, N.P. Padture, Inhomogeneous oxidation of $\mathrm{ZrB2}-\mathrm{SiC}$ ultra-high-temperature ceramic particulate composites and its mitigation, Acta Materialia, 129 (2017) 138-148.

[19] K. Kurokawa, H. Matsuoka, H. Takahashi, High Temperature Oxidation of MoSi2-WSi2Solid Solutions, in: Materials science forum, Trans Tech Publ, 1997, pp. 885-892.

[20] L. Silvestroni, D. Sciti, F. Monteverde, K. Stricker, H.J. Kleebe, Microstructure evolution of a W-doped ZrB2 ceramic upon high-temperature oxidation, Journal of the American Ceramic Society, 100 (2017) 1760-1772.

[21] J. Pang, W. Wang, C. Zhou, Microstructure evolution and oxidation behavior of B modified MoSi2 coating on $\mathrm{Nb}-\mathrm{Si}$ based alloys, Corrosion Science, 105 (2016) 1-7.

[22] D.B. Mahadik, S. Gujjar, G.M. Gouda, H.C. Barshilia, Double layer SiO2/A12O3 high emissivity coatings on stainless steel substrates using simple spray deposition system, Applied Surface Science, 299 (2014) 6-11.

[23] E. Sani, L. Mercatelli, M. Meucci, L. Silvestroni, A. Balbo, D. Sciti, Process and composition dependence of optical properties of zirconium, hafnium and tantalum borides for solar receiver applications, Solar Energy Materials and Solar Cells, 155 (2016) 368-377.

[24] F. Seronde, P. Echegut, J.P. Coutures, F. Gervais, Emissivity of oxides: a microscopic approach to glass coatings, Materials Science and Engineering: B, 8 (1991) 315-327.

[25] H.-Z. Liu, Z.-G. Liu, J.-H. Ouyang, Y.-M. Wang, Influences of lattice vibration and electron transition on thermal emissivity of $\mathrm{Nd} 3+$ doped $\mathrm{LaMgAl11O} 19$ hexaaluminates for metallic thermal protection system, 
Shao, Gaofeng, et al. "Improved oxidation resistance of high emissivity coatings on fibrous ceramic for reusable space systems." Corrosion Science 146 (2019): 233-246.

Applied Physics Letters, 101 (2012) 161903.

[26] H.-S. Kim, J.-K. Yoon, G.-H. Kim, J.-M. Doh, S.-

I. Kwun, K.-T. Hong, Growth behavior and microstructure of oxide scales grown on WSi2 coating, Intermetallics, 16 (2008) 360-372.

[27] K. Hellström, J.E. Tang, T. Jonsson, M. Halvarsson, R. Pompe, M. Sundberg, J.E. Svensson, Oxidation behaviour of a (Mo, W)Si2-based composite in dry and wet oxygen atmospheres in the temperature range $350-950{ }^{\circ} \mathrm{C}$, Journal of the European Ceramic Society, 29 (2009) 2105-2118.

[28] A. Yamauchi, T. Sasaki, A. Kobayashi, K. Kurokawa, Microstructure and Oxidation Behavior of Boron-Added WSi2 Compact, Materials transactions, 49 (2008) 2047-2053.

[29] T. Fleisch, G. Mains, An XPS study of the UV reduction and photochromism of $\mathrm{MoO} 3$ and $\mathrm{WO} 3$, The Journal of Chemical Physics, 76 (1982) 780-786.

[30] J.G. Choi, L.T. Thompson, XPS study of asprepared and reduced molybdenum oxides, Applied Surface Science, 93 (1996) 143-149.

[31] T. Sossaman, J.H. Perepezko, Viscosity control of borosilica by $\mathrm{Fe}$ doping in $\mathrm{Mo}-\mathrm{Si}-\mathrm{B}$ environmentally resistant alloys, Corrosion Science, 98 (2015) 406-416. [32] D.X. Li, Z.H. Yang, D.C. Jia, X.M. Duan, S.J. Wang, Q.S. Zhu, Y. Miao, J.C. Rao, Y. Zhou, Effects of boron addition on the high temperature oxidation resistance of dense $\mathrm{SiBCN}$ monoliths at 1500 degrees C, Corrosion Science, 126 (2017) 10-25.

[33] C. Wang, K. Li, X. Shi, J. Sun, Q. He, C. Huo, Self-healing YSZ-La-Mo-Si heterogeneous coating fabricated by plasma spraying to protect carbon/carbon composites from oxidation, Composites Part B: Engineering, 125 (2017) 181-194.

[34] Y. Zhang, P. Zhang, J. Ren, L. Zhang, J. Zhang, $\mathrm{SiC}$ nanowire-toughened MoSi2-WSi2-SiC-Si multiphase coating for improved oxidation resistance of C/C composites, Ceramics International, 42 (2016) 12573-12580.

[35] C. Zhai, Y. Niu, L. Huang, H. Pan, H. Li, X. Zheng,
J. Sun, Microstructure characteristics and oxidation behavior of vacuum plasma sprayed tungsten disilicide coating, Ceramics International, 42 (2016) 1879818805.

[36] X. Li, J. Feng, Y. Jiang, H. Lin, J. Feng, Preparation and anti-oxidation performance of Al2O3containing TaSi2-MoSi2-borosilicate glass coating on porous $\mathrm{SiCO}$ ceramic composites for thermal protection, RSC Advances, 8 (2018) 13178-13185.

[37] C. Xu, W. Gao, Pilling-Bedworth ratio for oxidation of alloys, Material Research Innovations, 3 (2000) 231-235.

[38] D. Berztiss, R. Cerchiara, E. Gulbransen, F. Pettit, G. Meier, Oxidation of MoSi 2 and comparison with other silicide materials, Materials Science and Engineering: A, 155 (1992) 165-181.

[39] T.C. Chou, T.G. Nieh, New observations of MoSi2 pest at $500^{\circ} \mathrm{C}$, Scripta Metallurgica et Materialia, 26 (1992) 1637-1642.

[40] T.A. Kircher, E.L. Courtright, Engineering limitations of MoSi 2 coatings, Materials Science and Engineering: A, 155 (1992) 67-74.

[41] M. Samadzadeh, C. Oprea, H. Karimi Sharif, T. Troczynski, Comparative studies of the oxidation of MoSi2 based materials: Low-temperature oxidation $\left(300-900^{\circ} \mathrm{C}\right)$, International Journal of Refractory Metals and Hard Materials, 66 (2017) 11-20.

[42] W. Shao, C. Zhou, Oxidation behavior of the Bmodified silicide coating on $\mathrm{Nb}-\mathrm{Si}$ based alloy at intermediate temperatures, Corrosion Science, 132 (2018) 107-115.

[43] M.F. Yan, J.B. Macchesney, S.R. Nagel, W.W. Rhodes, Sintering of optical wave-guide glasses, Journal of Materials Science, 15 (1980) 1371-1378.

[44] T. Karahan, G. Ouyang, P.K. Ray, M.J. Kramer, M. Akinc, Oxidation mechanism of W substituted Mo-SiB alloys, Intermetallics, 87 (2017) 38-44. 